Comparative Philosophy Volume 10, No. 1 (2019): 143-191

Open Access / ISSN 2151-6014 / www.comparativephilosophy.org

https://doi.org/10.31979/2151-6014(2019).100112

CONSTRUCTIVE-ENGAGEMENT DIALOGUE (1.3)

\title{
A FURTHER LOOK AT EXPLANATORY POTENCY OF CONSTRUCTIVE-ENGAGEMENT STRATEGY: REPLIES TO SORAJ HONGLADARON AND WEI SUN
}

$\mathrm{BO} \mathrm{MOU}$

I would like to thank Dr. Soraj Hongladaron and Dr. Wei Sun for their thoughtstimulating and engaging discussions of some parts of the constructive-engagement strategy in cross-tradition philosophical engagement ('CES' for short below). I truly enjoy reading their writings as I have learnt from their strategic insights and their specific treatments. Their critical discussions have provided me with effective channels to further elaborate some relevant major points of the CES and test its explanatory potency in treating the addressed issues in their engaging discussions.

In the following my strategy is this. First, in Section 1, to help the reader capture the theme of the current "constructive-engagement dialogue" section and put the subsequent discussions in a due background, I first give a big picture of the CES. Second, in Section 2, I reply to the major points in Dr. Hongladaron's critical discussion. Third, in Section 3, I reply to the major points in Dr. Sun's critical discussion. In so doing, I give a further look at the explanatory potency of the CES while showing its open-ended and inclusive character. Some relevant explanatory resources are in need but are given in the appendixes to avoid distraction from the major focus on my replies to the two scholars' critical discussions.

\section{A BIG PICTURE AND MAJOR EMPHASES OF CONSTRUCTIVE- ENGAGEMENT STRATEGY: BACKGROUND}

For the reader to have a big picture of the constructive-engagement strategy and have an easy cross-reference to some explanatory resources and lexical distinctions employed in my replies to the two scholars' engaging discussions, in this section, I first highlight the major methodological emphases of the CES and its structure of three related parts whose explanations are given respectively in three appendixes.

MOU, BO: Professor of Philosophy, San Jose State University, California, USA. Email: bo.mou@sjsu.edu 
The reflective practice that more or less, explicitly or implicitly, implements the constructive-engagement strategy in doing philosophy comparatively is not new; the theoretic endeavor intended to more or less explain some of the involved methodological emphases is not new either. However, remarkably in the past two decades (especially since the beginning of this century), some systematic collective efforts both in theory and in reflective practice have been made explicitly in the direction of the CES (for example, this journal with its 2010 inception and now in its tenth anniversary is one product of such collective efforts). My own efforts in the past two decades in this connection are parts of these collective efforts. Among others, I have endeavored to give a relatively systematic theoretic elaboration of the strategic purpose and methodological emphases of this cross-tradition-engagement movement in philosophy; in so doing, I intend to suggest an effective meta-methodological framework of cross-tradition/across-approach engagement in philosophy with its due explanatory potency.

The constructive-engagement strategy as a meta-methodological strategy concerning the goal and methodology in cross-tradition philosophical engagement (or doing philosophy comparatively), generally but briefly speaking, is this. It is to inquire into how, by way of reflective criticism (including self-criticism) and argumentation and with the guidance of adequate methodological guiding principles, distinct approaches from different philosophical traditions (whether distinguished culturally or by styles and orientations) can learn from each other and make constructive joint contributions (in a complementary, instead of incompatible, way) to the contemporary development of philosophy on a range of philosophical issues or topics, which can be jointly concerned and approached through appropriate philosophical interpretation and from a broader philosophical vantage point. ${ }^{1}$

The constructive-engagement strategy has six related methodological emphases (as highlighted in italics below) in a coordinate way: (1) it emphasizes critical engagement; (2) it emphasizes constructive contribution of each of the distinct parties in critical engagement through their learning from each other (though they might be not derivable from, or reducible to, each other) and making joint contribution to jointly-concerned issues in a complementary way; (3) it emphasizes philosophical interpretation of the addressed thinkers' texts instead of mere historical description; (4) it emphasizes the philosophical-issue-engagement orientation that aims at contribution to the contemporary development of philosophy and society on a range of philosophical issues that can be jointly concerned and approached through philosophical interpretation and from a broader philosophical vantage point; (5) it emphasizes that such engaging explorations need to be guided by adequate methodological principles; (6) it emphasizes being open-ended and inclusive regarding various (eligible) perspectives from distinct approaches in different

\footnotetext{
${ }^{1}$ For my previous presentations of the central resources of the "constructive-engagement" strategy and their modifications, see Mou 2001, 2006, 2010 and 2016, among others.
} 
traditions, through the foregoing emphases, and thus providing an effective and inclusive meta-methodological framework and platform of constructive engagement.

The central contents of the constructive-engagement strategy, when presented as a meta-methodological framework of cross-tradition/cross-approach engagement in philosophy, includes three closely related parts of its conceptual and explanatory resources: (i) the preliminary conceptual and explanatory resources regarding distinct methodological things together with lexical distinctions in need; (ii) explanatory remarks concerning the foregoing methodological emphases, especially the aforementioned emphases (3) and (4), on behalf of adequacy of the CES; (iii) to implement the above emphasis (5), a range of the suggested "adequacy" conditions for how to maintain adequate methodological guiding principles in looking at the relation between distinct perspectives when treating jointly-concerned issues. To avoid distraction from the main "replies" contents while enabling the reader to have a better understanding of these addressed explanatory resources in the subsequent "replies" contents, I briefly explain the explanatory resources in these three connections respectively Appendix 1, Appendix 2 and Appendix 3.

\section{REPLY TO HONGLADARON: HOW THE JOINTLY-CONCERNED OBJECT OF STUDY IN CROSS-TRADITION ENGAGEMENT IS POSSIBLE}

Dr. Hongladaron's engaging article is not long but rich in content. He raises, explicitly or implicitly, three reflectively interesting and engaging questions concerning how to understand the identity of an object of study in cross-tradition philosophical engagement and, more generally, the status and justification basis of the suggested adequacy conditions regarding how to maintain adequate methodological guiding principles in cross-tradition philosophical engagement. First, he explicitly raises the following concern: if two approaches from different traditions in a comparative examination set out to talk about two different objects instead of addressing the same object differently, how can we say they have a jointly-concerned object of study? For illustration, Dr. Hongladaron gives a comparative examination of Aristotle's and Buddhism's distinct metaphysical accounts of the world in which they seem to talk about different (or, in his terms, "completely different") objects of study. Indeed, such a concern would become prominent in view of one party's seeminglyreligion-related object of study, which is the case of Buddhism. In this way, as I see it, Dr. Hongladaron's concern actually (though implicitly) addresses a more general concern in cross-tradition philosophical engagement: how is it possible to jointly concern about a religion-related object of study in cross-tradition philosophical engagement? Third, in the ending passage, Dr. Hongladaron explicitly raises another significant issue concerning the status and justification basis of the suggested adequacy conditions for how to maintain adequate methodological guiding principles in cross-tradition philosophical engagement. In the following, I address the three concerns respectively in Section 2.1, Section 2.2 and Section 2.3, while further looking at the explanatory potency of the constructive-engagement strategy. 


\subsection{IDENTITY OF THE OBJECT OF STUDY UNDER PHILOSOPHICAL INTERPRETATION}

Dr. Hongladaron's first concern is put forward in this engaging way:

Perhaps the most important principle in his list is the first one: in Mou's words, "A methodological guiding principle is considered adequate (in this connection) if, given an object of study, it enables the agent to recognize that there is a way that the object objectively is such that it is not the case that "anything goes," and we can all talk about that same object even though we may say different things (concerning distinct aspects of the object) about it." (Mou 2018,1-2 [Mou 2016, 269-70]). In other words, an adequacy condition for a fruitful undertaking of comparative philosophy is that both sides recognize that there exists at least an object in common. The object presents itself as the bedrock reality, so to speak, upon which different theorization about it can take place. According to Mou, "anything goes" when even this self same object is not recognized by both sides of the philosophies being compared. Perhaps "anything goes" when one side of the philosophies being compared does not even recognize that there exists an individual object; then presumably there is nothing to be compared as both sides would talk past each other since there is nothing they are talking about in common, there being no anchor point.... w would like to...show that in some cases comparative philosophy and constructive dialogs between different philosophical traditions could indeed take place successfully even without sharing an objective individual thing that Mou argues for. This, however, does not imply that "anything goes" because both the traditions can engage in a common enterprise even though they don't share any individual object in common. My example will come from comparing Buddhist philosophy with Aristotle's philosophy on individuals. The Buddhist and the Aristotelian can, as I shall argue, engage in a very constructive dialogue with each other even though they don't share anything in common in their respective ontologies. (Hongladaron 2019, 119)

In the subsequent discussion in this section, I give three evaluative explanations on the interesting and engaging points that Dr. Hongladaron makes in the above cited passage. The first and the second ones are quite straightforward for the sake of clarifying what I have actually mean by the involved key terms; I can reiterate them by due citations in my previous writings. I will say more in my third explanation which I consider to be an effective opportunity to show the explanatory potency of the constructive-engagement strategy in this connection.

First, in my original account, an object of study is not restricted to an "individual" object over there; rather, the identity of a (genuine) object of study in philosophy is understood broadly: an object of study can be a naturally produced individual object in physical reality, a socially constructed object in social reality, an abstract object out of theoretic construction, a "linguistic" object introduced linguistically, a thinker's text, or an issue (topic or problem) for debate or critical discussion in philosophical inquiries as an object of philosophical study (see Mou 2010, 9). In philosophical inquiries, among others, two most often addressed (types of) objects of study are these: (1) this natural world as a whole that is jointly designated in various metaphysical accounts concerning the fundamental features of humans' surrounding 
environment; this point will be further explained below; (2) an issue that is jointly concerned in philosophical inquiries (such as the issue of filial piety jointly concerned in Socrates' and Confucius' teachings which I address for illustration in my 2010 essay). It is noted that some issues in philosophy turn out to focus on distinct aspects of a larger issue, just like some objects of study in philosophy turn out to be distinct aspects of a more comprehensive object of study. Both types of objects of study are especially relevant to the subsequent discussion.

Second, related to the foregoing point, the addressed "objective" character of an object of study in philosophy does not mean that the object must be just over there as an individual object in time and space, whose existence totally independently of humans' creation; rather, the point is this: once an object is given (whether it is given as a physical individual object or a socially constructed object in social reality or an abstract object out of theoretic construction or a "linguistic" object that is introduced linguistically), the object objectively is such that it is not the case that "anything goes," and we can all talk about that same object even though we may say different things (concerning distinct aspects of the object) about it.

Third, the genuine identity of an object of study as a jointly-designated object of study or a jointly-concerned issue in across-tradition philosophical engagement is not exclusively determined by the thinker(s)' own description(s), which can be (partially) false, but needs to be identified and characterized through philosophical interpretation. I plan to say more on this because it directly relates to two closely related methodological emphases of the constructive-engagement strategy, i.e., that on philosophical interpretation of the addressed thinkers' texts instead of mere historical description and that on the jointly-concerned-philosophical-issue engagement. My reply in this connection consists of the following seven related points.

(1) Generally speaking, the presences of different "metaphysical" descriptions concerning the fundamental features of reality imply neither that these different descriptions must be about different worlds nor that they must bring about different worlds: these different "metaphysical" descriptions do not imply the former because they might be about the same world; they do not imply the latter because each of them is supposed to describe the world that is logically and metaphysically prior to its description, rather than the world that is to be created by such a description.

(2) Specifically speaking concerning the current case, given that Aristotle's account is about this natural world, the fact that the Buddhist account differs from Aristotle's does not automatically imply that the Buddhist account is about the world that does not include the same natural world, even if or given that the world that Buddhism talks about might be supposed to also include the "karma" world and (for the sake of argument) that the "karma" part of this world exists (as Buddhism claims).

(3) Now what is at issue is this: does the Buddhist account also talk about the same nature world as that talked about by Aristotle's account to the extent that this natural world is at least the primary part of the world about which the Buddhist account talks (if what both talk about would not be exactly the same world), instead of a "completely different" world? It is noted that, insofar as the basic points of the Buddhist account are made based on Buddhists' life experience in this natural world, 
of which humans are parts, and addresses the impermanent "becoming" feature of this natural world, to this extent, they are fundamentally about this natural world, rather than some world else that is separate or beyond and above this natural world, whether or not this natural world is considered to be the entire world they talk about or just part of it. Furthermore, the current case can be settled in a stronger way by looking at the intrinsic characters of both sides' accounts. Let us see how and why. One most relevant and important characteristic feature of both accounts is this: each of Aristotle's and Buddhism's basic metaphysical accounts addresses the most fundamental and unifying features of the surrounding environment which humans inhabit; consequently, such most fundamental features that they address are supposed to be possessed by the entire world, including the world that the other party designates; therefore, the world that possesses the addressed fundamental features must include the world that each other talks about because it is what each other's most fundamental features are supposed to cover; and this "overlapped" part of the world that is supposed to possess the most fundamental features is their jointly designated world (part). And this jointly-designated world has to include this natural world as its core part, whether or not one side or both sides of the debate over the fundamental character of the world would intend to cover something (some world part) more than this natural world (say, for Buddhism, the "karma" world part), because, for one thing, both sides make their claims based on their observations of this same natural world in which they live and about which they talk, as indicated before; for another thing, both sides themselves are parts of this natural world when they talk about themselves and about their own living environments while addressing the most fundamental features of the world that are supposed to apply to themselves and their living environments. In this way, the foregoing line actually constitutes one fundamental rationale for why all these metaphysical accounts that are set out to identify and explain the most fundamental features of the world are eventually forced or have to observe "the same natural world" norm to the effect that they essentially talk about the same natural world, whether or not historically speaking they themselves actually recognized or were willing to admit it, a point relate to another point of philosophical interpretation, to be further explained below.

(4) Furthermore, insofar as Dr. Hongladaron does not resort to the "karma" part of the world that the Buddhist account talks about, and with the reasonable assumption that he as a philosopher focuses on the philosophical dimension of the Buddhist account, we can make a stronger but reasonable statement in this context: the world about which the "deflationary" Buddhist account under Dr. Hongladaron's philosophical consideration talks is just this same natural world as that about which Aristotle's account talks, although they point respectively to distinct aspects or layers of the same natural world, i.e., the "becoming" layer to which the "becoming"-aspectconcerned perspective of Buddhist account points and the "essence" layer to which the "essence"-aspect-concerned perspective of Aristotle's account points.

(5) With the foregoing points in view, the relevant resources concerning the issue of reference in contemporary philosophy of language can further help us understand how the jointly-designated and jointly-concerned object of study in this case is 
possible. It is known that there is the significant debate between the Fregean "descriptive" model of reference and the Kripkean "causal-communicative" model of reference in contemporary philosophy of language. ${ }^{2}$ However, what are relevant here (or what I intend to resort to in treating the current case) are not those really controversial or incompatible parts but some of those complementary parts in their accounts. If the foregoing point on Aristotle's and Buddhism's respective accounts on the fundamental features of the world jointly designate this same natural world is on the right track, on the one hand, the Kripkean "causal-communicative" model (or a more inclusive "communication-link" model) of reference can provide an effective explanation of how peoples respectively or jointly on the Aristotelian track and on the Buddhist track can jointly designate and continually talk about the same natural world through their distinct communicative links; on the other hand, in terms of Frege's classical distinction between sense (Sinn) and reference (Bedeutung), the Fregean "descriptive" model of reference can provide an effective explanation of how peoples respectively or jointly on the Aristotelian track and on the Buddhist track can jointly talk about the same natural world differently through their distinct perspectives via distinct "senses": these distinct perspectives point respectively to some distinct aspects, layers or dimensions (among others, the "essence" attribute and the "becoming" attribute) of the same natural world via distinct descriptions that denote distinct attributes of the same natural world and thus give distinct "senses" as distinct modes of presentation of the same natural world.

(6) Now it is the time to give an analysis of the very idea of "common meaning" addressed in Dr. Hongladaron's account for the sake of Aristotle's and Buddhism's accounts achieving each other's mutual understanding. Dr. Hongladaron presents his idea of "common meaning" this way:

"...the number one methodological principle would be that either side knows the content of the other side well enough to be able to understand the point and the arguments of the other's side fully.... A possible challenge to Mou's First Principle is how one knows that the object being discussed in comparative philosophy is one and the same...how to tell that both sides are actually talking about the same thing, and I have answered that both sides need to share largely the same description of the thing being talked about. This can only be done if both sides speak a common language as we have seen, and a necessary condition for this is that both sides understand the other's position well enough. So the issue becomes a search for an anchor of common meaning so as to act as a guarantee that both sides do really understand each other even if they do not agree. Common meaning can only be established through long period of assimilation into the atmosphere, or the world, of the other side.... They not only have to master their own native tradition; they instead must belong to two native traditions, in the same way as one who is a bilingual can switch back and forth effortlessly between two languages." (Hongladaron 2019, 123)

It is fair to say that by 'common meaning' Dr. Hongladaron means something common like an 'anchor' on which both sides of the debate (or those interpretation

\footnotetext{
${ }^{2}$ For a recent clear presentation of the debate and a range of the engaging issues, see Cappelen $\&$
} Dever 2018. 
makers) can reach their due understanding of the meanings of the language presentations of each other's (or both sides') metaphysical accounts. Nevertheless, it seems unclear what Dr. Hongladaron means by such an anchor-like common meaning. It is known that, as elaborated in contemporary philosophy of language, the meaning of a linguistic expression [say, a common name or description that is to talk about a thing (an object or a collection of objects) as its referent] consists of its intersubjective literal sense and its referential meaning (among others) for the sake of understanding the linguistic expression: any understanding of a linguistic expression that is to talk about some extra-linguistic object without capturing its referential meaning is doomed to being fundamentally incomplete. Indeed, different speakers can talk about the same referent as a whole differently via distinct descriptions (with their distinct senses); the referent as a whole constitutes the anchor-like "common" meaning to the extent that it is the common referential meaning about which all these distinct descriptions talk. Now, as explained above, each of Aristotle's account and the Buddhist account addresses the most fundamental features of the surrounding environment which humans inhabits; such most fundamental features that they address are supposed to be possessed by the entire world, which includes the "overlapped" world that is thus jointly designated; their jointly designated world (part) as their joint-designated "common" referential meaning constitutes one anchor-like common basis for their mutual understanding.

(7) Last but never least, the foregoing points [especially, (3), (5) and (6)] are related to the point of philosophical interpretation in contrast to mere historical description. One might raise the following question: is your point that Aristotle and a Buddhist thinker must accept a common object in the sense (a) that they must both assert common claims about the object or in the sense (b) that they must both theoretically comprehend the claims of the other? The point here is neither (a) nor (b) but this: through philosophical interpretation, we can realize that the two thinkers actually talk about the same natural world as the common object to the extent as specified in (3) and that their distinct accounts of the world share the jointlydesignated "common" referential meaning, whether or not, historically speaking, they themselves actually recognize or were willing to admit it and whether or not the idea of the jointly-designated "same" natural world as the "common" referential meaning were actually running in those ancient thinkers' heads. More explanation on the point of philosophical interpretation in cross-tradition engagement is given in Appendix 2. The relevant point of philosophical interpretation to the current case will be reiterated in the ending paragraph of Section 2.

At this moment, one note is due. Through the foregoing explanation and illustration, we can also see why all those metaphysical accounts that are set out to identify and explain the most fundamental features of the world eventually have to observe the "same-natural-world" norm to the effect that they actually talk essentially about the same natural world of which humans are parts, whether or not they themselves actually recognized or were willing to admit it." If the "same-object-

\footnotetext{
${ }^{3}$ See the relevant discussion in section 2 of Appendix 4.
} 
recognizing" adequacy condition under examination needs to be observed as a normative basis for cross-tradition philosophical engagement and thus can be treated as the "same-object-recognizing" norm, the "same-natural-world" norm constitutes one prominent, significant and fundamental manifestation or variant of the "sameobject-recognizing" norm in cross-tradition philosophical engagement. Indeed, both in folk talks in our daily lives and in reflective talks in philosophy, generally speaking, perhaps one object we all talk about most often (explicitly or implicitly) and fundamentally is this natural world as our surrounding environment of which humans are parts. The same-natural-world norm requires and enables the agent to recognize that people can all talk about the same natural world while talking about it differently, through distinct perspectives that point to and focus on different aspects or layers of it, with the due understanding of the identity of the natural world: we as humans are parts of the natural world; its existence/development together with its fundamental principle as a whole is eventually and fundamentally independent of how humans think of it and beyond the humans' control; and any "local" principles of its parts are to be in accordance with its unifying "global" fundamental principle. So to speak, this basic same-natural-world norm manifests its power in two connections or through two ways: (i) the "same-natural-world" norm plays its direct guiding role in regulating our reflection on this natural world: we can all talk about the same natural world even though we may say different things (concerning its distinct aspects or layers) about it; (ii) because the natural world directly, indirectly or arguably constitutes the fundamental metaphysical foundation for a range of the fundamental human concerns, especially a range of issues in various subjects in philosophy (such as human morality), the same-natural-world norm plays its fundamental guiding role through providing a due base for understanding the metaphysical foundation, source or direction of the adequate ways of these fundamental human concerns; to this extent, our reflective explorations of these fundamental human concerns need to be eventually based on and resort to the same-natural-world norm.

\subsection{HOW THE RELIGION-RELATED OBJECT OF STUDY IS POSSIBLE IN CROSS-TRADITION PHILOSOPHICAL ENGAGEMENT}

Dr. Hongladaron's concern actually (though implicitly) addresses a more general issue in cross-tradition philosophical engagement: how is it possible to jointly concern about a religion-related object of study in cross-tradition philosophical engagement? Although Dr. Hongladaron does not directly and explicitly address this issue, and although his discussion focuses on the philosophical dimension of the Buddhist religion-related account of the world without resorting to such religiouslyoriented Buddhist ideas as the "Samsara"/"karma" account, Buddhism as a whole is a religiously-oriented movement of thought, and Buddhist thought as a whole has its religious dimension and its philosophical dimension. Then the foregoing general issue can be put in more specific terms concerning the current case: if, as explained in the previous sub-section, the natural-world dimension of what Buddhism talks about in its metaphysical account can be a jointly-concerned object of study, how about its 
religious (or religiously-oriented) dimension that addresses the account of some other kind of the world than this natural world (such as the "karma" world), whether or not, (or no matter to what extent) such an account is true? In other words, can this part be the jointly-concerned object of study in cross-tradition philosophical engagement, given that philosophical inquiries and religious inquiries are not the same thing and that, say, a journal in comparative philosophy is not just a journal in comparative religion (or comparative religious studies)? This issue has its general significance in cross-tradition philosophical engagement, as we can raise similar questions concerning those religion-related inquiries that have been considered to be parts of philosophy or the philosophical dimensions of several major movements of religion, such as Christian philosophy as the philosophical dimension of Christianity and Islamic philosophy as the philosophical dimension of Islam (the religion of the Muslims), although Buddhism is considered more secular in contrast to, say, Islam and Christianity.

This issue is substantially related to Dr. Hongladaron's directly addressed question of whether Aristotle's and Buddhism's metaphysical accounts have their jointly designated object of study (treated in the previous section): a stronger case can be made in the following sense. Now, for the sake of argument, given that Aristotle's and Buddhism's "metaphysical" descriptions would bring about two different realities and thus do not talk about the "same" world (even without the "overlapped" natural world as a jointly designated object of study), they actually both address the jointlyconcerned issue of the fundamental features of the world, whether or not the world as a whole that the traditional Buddhist account talks about and the world as a whole that Aristotle's account talks about are the same or somehow (or even completely) different. ${ }^{4}$ (For the sake of argument, we can assume that they are different at least to the extent that the natural world that Aristotle talks about is only part of the world that Buddhism talks about or even that the "karma" world not only exists but also has thoroughly transformed what we understand as the natural world into some totally different world.) As already emphatically addressed above, the identity of an object of study can be a jointly-concerned issue in philosophy; now both Aristotle and Buddhism address the "jointly-concerned" philosophical issue of what constitute the fundamental characteristics of reality or the "jointly-concerned" philosophical issue of how things are holistically connected in a causal or network way, even if the realities that they respectively talk about would be different or even completely

\footnotetext{
${ }^{4}$ Actually, in the case of Aristotle's and Buddhism's metaphysical accounts, what they can jointly concerned with are not restricted to the issue of the fundamental features of the world. As far as the karma case is concerned, first, to what extent Aristotle would accepts an account of karma would much depend on how karma is understood: if it is defined in terms of character development (say, becoming courageous by performing courageous acts), then it would be quite Aristotelian; second, even if Aristotle does not accept karma, and given that he presumably accepts basic claims about causation, a causation-oriented account of karma might be theoretically available to him. The point is that Aristotle does not have to share largely the same description of karma as that in Buddhism for the sake of understanding the karma account in Buddhism. Thanks go to Christopher Framarin for his pointing out this to me.
} 
different: for Aristotle, it is our surrounding natural world; for Buddhism, let us follow what its advocates say (whether or not such a saying is true): it is essentially a "religious" one which as a whole is (considered to be) intrinsically related to the "karma". So, even for the Buddhist "karma" account of reality, we can still identify a certain jointly-concerned object of study (as the jointly-concerned issue of what constitute the most fundamental characteristics of the world), sensitive to the purpose and focus of a certain specific project, in cross-tradition philosophical engagement.

In this way, in response to Dr. Hongladaron's concern, a stronger case than what is presented in the previous section can be made concerning how Aristotle's account and the Buddhist account as specified by him have their jointly-concerned object of study in two connections: (i) whether or not the involved historical figures did actually recognized or were willing to admit it, both sides really talk about the same natural world to the extent as explained in the previous section; (ii) even if (for the sake of argument) their distinct "descriptions" bring about two radical different worlds, both sides address the jointly-concerned issue of the fundamental feature of the world in the way as explained above.

It is noted that the foregoing second type of jointly-concerned objects of study as jointly-concerned philosophical issues have general significance in cross-tradition philosophical engagement, especially relevant to the religiously-oriented account addressed in cross-tradition philosophical engagement. Let us give a further look at how it is possible to have such jointly-concerned philosophical issues in such contexts. One crucial element lies in this: there are parts (philosophical dimensions or strands) in such religiously-oriented accounts that set out to not only (more or less) capture the fundamental ways humans' lives and their surrounding environment are (thus related to philosophical inquiries regarding a range of fundamental concerns) but are also up to philosophical critique and justification if the strategic goal includes the pursuit of truth [to capture the way things are (to be)], neither for merely playing intellectual games nor for just pleasing any absolute authority. When they are identified in such philosophical way in cross-tradition engagement, they thus address jointly-concerned philosophical issues, either actually or potentially: actually, when such issues are already addressed in cross-tradition philosophical engagement; potentially, when such issues have yet to be explicitly addressed but can be explicitly jointly addressed in current or future cross-tradition philosophical engagement.

Perhaps one effective illustration of the foregoing second type of jointlyconcerned objects of study as jointly-concerned philosophical issue is the case of the religiously-oriented prophecy discourse in Islamic philosophy (or the Islamic Peripatetic tradition that includes the prophecy discourse as one significant portion of this tradition). ${ }^{5}$ How can one look at the due relationship between the critique/ justification character of philosophical activities and the imagination power of prophecy? Should such imagination be regulated by adequate critique/justification or eventually be based on the absolute religious faith in God (in the Islamic sense of the term)? If the imagination power of prophecy is up to philosophical critique/

\footnotetext{
${ }^{5}$ This illustration paragraph is an excerpt from section 2 of Mou 2012.
} 
justification, then both can be compatible or even somehow mutually enhanced. If the imagination power of prophecy is supposed to be regulated merely or eventually by God or the absolute faith in God, one would further question the philosophical nature of Peripatetic tradition while acknowledging and appreciating the value of the prophecy. It is true that, historically speaking, philosophy and religion were not separated from each other at earlier (or even recent) stages of development of various (culture/region-associated) philosophical traditions as thinkers (say, in ancient times) did not explicitly make the conceptual distinction between intellectual disciplines that we do; it is also true that some religion-related discourse (topics and resources) might be closely related to a philosophical movement in some traditions (for example, the current case concerning the prophecy discourse in Islamic philosophy). Nevertheless, this amounts to saying neither that there are no significant conceptual distinctions between those inquiries, nor that we cannot reflectively and effectively focus on one dimension of the whole in the subsequent reflective examination (say, its philosophical dimension) nor that we cannot creatively transform a historical religiously-oriented discourse into a philosophically-oriented discourse employing some relevant and philosophically interesting resources from the previous discourse. We can do that, depending on the primary purpose of a project in reflective examination. For one thing, if one's primary purpose is to examine how an idea or approach in one tradition could contribute to some philosophical issue together with some other approach (either from the same tradition or from another tradition) instead of just giving a historical description, then one is entitled to focus only on the philosophical dimension or even only on some aspect(s) of the philosophical dimension most relevant to the current concern. For another thing, scholars in contemporary studies of Islamic philosophy are indeed entitled to distinguish two kinds of prophecy discourse, i.e., (i) the (philosophically-oriented) prophecy discourse that is supposed to be regulated by adequate critique/justification, and (ii) the (religiously-oriented) prophecy discourse that is supposed to be regulated merely or eventually by God or the absolute faith in God, even if it might be the case that the former prophecy discourse, (i), was not historically produced but is reflectively and creatively produced by contemporary scholarship in Islamic philosophy for the need of philosophical inquiry. At this point, two notes are due regarding the relation between philosophy and religion. First, indeed, when giving a specific account, a philosopher also has to stop somewhere, i.e., the most basic principle of that account; what would really distinguish the "philosophical" nature of this philosopher and her work on the account lies in her "philosophical" attitude towards her most basic principle of the account: it is open to any criticism, instead of being treated as the absolutely unchallengeable "faith"; she is always ready to give it up when it turns out to be incorrect through philosophical critique and justification. Second, one might question: isn't it that a person who studies religion on her own will have a similar mindset to that of a philosopher by critique and justification? That might be the case, given that person who studies religion on her own sets out to subject any part of her inquiry open to criticism; if that person treats some part (say, her absolute faith) in her account as the final absolute authority on the issue that is not open to criticism, then 
there would be some crucial difference between treating the issue as a thoroughly "philosophical" issue and treating it merely partially "philosophical" issue in that connection. Such "philosophical" character is another substantial layer of the identity of the "jointly-concerned" philosophical issue.

\subsection{THE STATUS AND JUSTIFICATION BASIS OF THE SUGGESTED ADEQUQCY CONDITIONS}

In the ending passage, Dr. Hongladaron raises another significant issue concerning the status and justification basis of the suggested adequacy conditions for how to maintain adequate methodological guiding principles in cross-tradition engagement in philosophy through two related general questions: (1) "What justifies" this set of adequacy conditions? (2) "Which philosophical tradition do" these adequacy conditions "fall under?" He gives his own brief answers to the questions this way:

If the Principles are the products of Western philosophy, then it shows that Western philosophy has precedence over the other, non-western tradition that is being compared with it, precisely because the methodology governing the comparison falls under the domain of Western philosophy.... The principles need to be clearly metarules. Its status as neutral metarules can only emerge after a long period of internalization as I have said before, and even so it can only emerge piecemeal, as a result of trials and errors when the result of the comparison...is presented to the wider circle of philosophers, .... In the absence of an absolute gold standard of philosophical truth, this is all we have. To speak of the matter in contemporary terms, this means that methodological principles such as Mou's cannot belong to any tradition in particular (such as Western analytic philosophy) but has to belong to all traditions at the same time. (Hongladaron 2019, 125-6)

I agree with Dr. Hongladaron about the importance of the aforementioned questions he addresses about these adequacy conditions. I also agree with Dr. Hongladaron to the "meta-rule" character of these adequacy conditions that should be applicable to various cases in cross-tradition philosophical engagement (if this is part of what is meant for their being 'neutral' instead of "belong[ing] to" one tradition alone). Indeed, both "theoretically" speaking and "practically" speaking, the suggested adequacy conditions for maintaining adequate methodological principles are set out to go that way. In the following, I would like to make several engaging remarks related to Dr. Hongladaron's ideas presented in the foregoing cited passage and in view of the two questions that he raises here.

Let me first consider in which sense an idea in philosophy (say, an "adequacy condition" idea that has been suggested by this author) is said to "belong to" or not "belong to" a tradition. Although I am not sure exactly what Dr. Hongladaron means by 'belong to' and 'cannot belong to' here, in view of the context in which the phrases appear, I guess he might mean one, or more than one, of several things: (1) historically speaking, it "belongs to", one tradition instead of another tradition; (2) conceptually speaking, it is intrinsically related to, and thus "belongs to", one tradition instead of some other tradition; (3) as far as its "production" process is 
concerned, they result from cross-tradition "comparative" exploration, instead of just through considering the resources in one tradition, and thus "cannot belong to" one tradition; (4) as far as its normative goal is concerned, it is set out to be "meta" in nature and thus applicable to cross-tradition exploration, instead of just one tradition within; (5) related to the preceding expectation, and as far as its explanatory potency is concerned, it should have its effective explanatory force and contribute to our understanding and treatment in cross-tradition engagement in philosophy. Now let me make my remarks in view of these lines. So to speak, the first four can be explicitly judged in view of their related matters of fact, while the last one needs the test of cross-tradition engagement practice. First, historically speaking, some of the ideas involved in the suggested adequacy conditions can be traced back to relevant resources in classical Chinese philosophy, though they are elaborated through philosophical interpretation and presented partially in terms of clear and effective conceptual resources and distinctions that are worked out for the sake of better understanding: for example, Zhuang Zi's version of transcendental perspectivism, Gongson Long's idea of relative identity, the Later Mohist's approach to semantic sensitivity, etc. Second, conceptually speaking, these adequacy conditions, even if some of their resources come from, and thus historically "belong to", one or another tradition, are not intrinsically associated with, and thus do not belong to, any ad hoc tradition(s) but contribute to the human common philosophical wealth. Third, as briefly indicated before, they result from the cross-tradition "comparative" exploration of distinct resources from different philosophical traditions in the past two decades, and thus "cannot belong to" one tradition. Fourth, as emphasized before, these "adequacy condition" resources are meta-methodological in nature and are set out to be applicable in cross-tradition philosophical engagement. Fifth, indeed, whether or not these "guiding-principle" resources are really effective and applicable to cross-tradition explorations or whether or not they are adequate enough to have strong explanatory potency is up to be tested in the past, present and future reflective practice of cross-tradition philosophical engagement, instead of a purely theoretic issue: the point in this connection can be vividly delivered by a Chinese proverb: “是 騾子是馬，拉出來遛一遛” (“To see whether it is a mule or a horse, let us walk it around"). At this moment after the completion of a range of collective projects that have been consciously guided by these methodological guiding principles resources (including many research articles published in this journal), I would like to say that they have effectively shown these resrouces' explanatory potency at least to the following extent: the participants' cross-tradition engagement efforts have been well implemented, and, with their collective research results being published, they have substantially enhanced our understanding and treatment of a range of significant jointly-concerned philosophical issues under examination. In view of several possible meanings of 'belong to' and 'cannot belong to' as addressed above, and based on the matters of fact in the foregoing five connections, I am afraid that it would be quite puzzling to either explicitly assume or implicitly suggest that these adequacy conditions together with its associated resources concerning guiding principles are "the products of Western philosophy" or "belong to" "Western analytic philosophy". 
Another reply line here is related to the "piecemeal" approach to metamethodological guiding principles and their justification basis. Dr. Hongladaron indicates that the addressed meta principles "can only emerge piecemeal, as a result of trials and errors when the result of the comparison... is presented to the wider circle of philosophers." Although I am not sure what 'piecemeal' approach exactly means here regarding the normative and unifying character of such meta-methodological guiding principles, it might mean this: the pursuit (process and goal) of such guiding principles in cross-tradition philosophical engagement cannot be normative and unifying in character or normatively related. If so, although I do render eligible a "piecemeal" approach as one perspective at certain stages of certain specific projects, I am afraid that philosophical pursuit needs to be carried out with its certain normative goal and unifying criteria as meta guiding principles, although such guiding principles do not render other kinds of intellectual or spiritual pursuits unworthy (such as some religious groups' spiritual practice of praying for God); otherwise, it would eventually run into difficulties in two connections: first, if merely "piecemeal", there would be no across-the-board normative criteria for carrying out philosophical pursuit instead of doing something else; second, if just "piecemeal", there would be no reasonable normative expectation even in the process of "trials and errors" which Dr. Hongladaron addresses: what would guide the "trials" and what would serve as the criteria for "errors"? One might respond: just anything that works; then a further question is this: it works for what? what counts as "works"? The point is this: to the above extent, an exclusive and thorough "piecemeal" approach in this connection is neither tenable nor possible if one really intends to carry out philosophical inquiry instead of doing something else or "anything goes", although I do render eligible and valuable a "piecemeal" approach as one (non-exclusive) perspective at certain stages of certain specific projects in philosophical pursuit (including pursuing meta-methodological guiding principles).

It is hoped that the preceding discussion also illustrates the two emphases, among others, of the constructive-engagement strategy as highlighted in Section 1, i.e., (3) it emphasizes philosophical interpretation of the addressed thinkers' texts instead of mere historical description, and (4) it emphasizes the philosophical-issue-engagement orientation aiming at contribution to the development of philosophy on a range of philosophical issues that can be jointly concerned and approached through philosophical interpretation and from a broader philosophical vantage point, both of which involve philosophical interpretation. More specifically speaking, the preceding discussion can illustrates several related aspects of philosophical interpretation relevant to the current case: among others, (i) elaborating due implication of the text of a thinker under examination (e.g., the underlying referential meaning) which, historically speaking, might be not actually running in the thinker's head but relevant to the focus of the examination; (ii) identifying the jointly-concerned philosophical issue that is (explicitly or implicitly) addressed in the text and that is related to the goal and focus in the current examination; (iii) capturing how the perspective suggested in the text is related to some other perspectives on the issue suggested in other thinkers' texts ; (iv) being sensitive to philosophical criticism and justification. 


\section{REPLY TO SUN: A VALUABLE SYNTHETIC ENDEAVOR}

Dr. Wei Sun addresses a significant meta-methodological issue of how to adequately look at the relationship between the two different meta-methodological approaches in comparative philosophy, i.e., the approach that he labels 'Ames' pragmatic approach' and the "constructive-engagement" approach. To show how "we may employ both approaches" (Sun 2019, 127), Dr. Sun first highlights what he considers to be the major points of the two approaches and then carries out a thoughtful comparative case study of Xun Zi's Dao approach and Aristotle's Eudaimonia approach on the issue of human happiness. The substantial content of his comparative case study makes a valuable contribution to the scholarship of comparative philosophy on the issue, while my reply below, with consideration of the main purpose here, focuses on the methodological dimension of his case study that sets out to combine parts of the two methodological approaches. Thanks to Dr. Sun's thoughtful exploration, I treat this discussion as a good opportunity to test the explanatory potency of the constructiveengagement strategy in view of its open-ended character. My strategy below is this. First, in Section 3.1, I give an analysis of the methodological dimension of the pragmatist approach that is advocated and defended by David L. Hall and Roger T. Ames ('the Hall-Ames approach' for short below), with consideration that a fair and reasonable evaluation of Dr. Sun's "synthetic" approach substantially relies on a careful understanding of the structure and content of the methodological dimension of the Hall-Ames approach. ${ }^{6}$ Second, in Section 3.2, I give an evaluative examination of the methodological dimension of Dr. Sun's comparative case study.

\subsection{AN ANALYSIS OF THE HALL-AMES PRAGMATIST APPROACH: PRAGMATIC PERSPETIVE AND PRAGMATIST GUIDING PRINCIPLE}

David L. Hall and Roger T. Ames" "pragmatist” approach as systematically presented in their three co-authored books (Hall \& Ames 1987, 1995 and 1998) is one of the most influential and systematic meta-methodological approaches in the areas of studying Chinese philosophy and comparative philosophy. Hall and Ames are the scholars who are well respected by myself as I have learnt much from their academic writings and as I have had my first-hand experience with how they handled relevant academic things in their remarkable professional and nice ways. ${ }^{7}$ However, from the

\footnotetext{
${ }^{6}$ This representative approach in cross-tradition philosophical engagement is labeled 'the Hall-Ames approach' with the name 'Hall' being listed before the name 'Ames', neither 'the Ames-Hall approach' nor simply 'the Ames approach', for two considerations. First, I respect these two authors' own preference (mutually-agreed arrangement) of the order of listing their names in their co-authored works - among others, Hall \& Ames 1987, 1995 and 1998, from which the resources of what I label 'the HallAmes approach' come. Second, though Hall has passed away, Professor Ames might possibly further develop his own ideas on the topic that might be substantially different from what are delivered in their co-authored works; to this extent, the two labels 'the Hall-Ames approach' and 'the Ames approach would have different meanings.

${ }^{7}$ Professor David Hall is one of the contributors to my edited volume 2001a which emphasizes distinct engaging views on the volume theme; he enthusiastically accepted my invitation for contribution and
} 
constructive-engagement vantage point, I partially agree and partially disagree to the Hall-Ames approach. Generally speaking, on the one hand, I agree to a "pragmatic" (methodological) perspective as one effective and valuable methodological perspective whose status and eligibility can be evaluated in view of the identity of an object of study and which can be taken being sensitive to the agent's purpose and focus. However, on the other hand, I disagree to some "pragmatist" (methodological) guiding principles as advocated and defended by the Hall-Ames approach. Clearly, in so saying, the substantial distinctions between the "pragmatic" and the "pragmatist" and between the methodological perspective and the methodological guiding principle are made, which are substantial conceptual resources and lexical distinctions for the subsequent discussion.

With the distinction between the methodological perspective and the methodological guiding principle explained in Appendix 1, let me start with a terminology clarification of the two related key terms 'pragmatic'/'pragmatics' and 'pragmatist'/'pragmatism' and make the distinction between the "pragmatic" perspective and the "pragmatist" guiding principle for the sake of clearly and effectively understanding and characterizing the methodological dimension of the Hall-Ames approach and exactly where the constructive-engagement strategy and the Hall-Ames approach engage with each other. The addressed distinction is not mere verbal one but points to some crucial connection in which we can distinguish an innocent or even expected "pragmatic" perspective from a certain "pragmatist" guiding principle that can be problematic and in which some fundamental difference between the Hall-Ames approach and the constructive-engagement approach can be identified. Given that, in view of the standard sense and conventional usage of the term 'pragmatic' in contrast to those of 'semantic' and 'syntactic' (as elaborated in philosophy of language) and of the conventional usage of the suffix '-ist'/'ism' in philosophy, the term 'pragmatic', as strictly used, means a situated uses of language which involve particular speech-act-utterance contexts and the language users' (particular) intentions (or their situated "epistemic" attitudes), or the study of what

was the first submitting his essay (Hall 2001), which perhaps is his last publication before he passed away in 2001. Although Professor Ames already knows that my approach is substantially different from his "pragmatist" approach, and although I do not belong in his "Hawaii" group, I have experienced how he is supportive and maintains fair and professional treatment with his large breadth of heart-and-mind. For one example, he is one of the external evaluators whom my university invited for evaluating my dossiers respectively for my tenure/promotion assessment in 2004 and for my early promotion to full professor assessment in 2008, he made his strong recommendations, stating that "I believe that Professor Mou has achieved the rank of full professor in our discipline as it has been defined in a standard Carnegie Research I institution" (cited from his evaluation letter of 2008). For another example, when this journal (Comparative Philosophy) was about to make its debut in 2010, without my request, Prof. Ames offered a two-page-long space to publish the "Announcement: New International Journal in Comparative Philosophy" in his then edited journal of repute, Philosophy East and West [59.4 (2009)]. I appreciate their remarkable professional way and Confucian jun-zi (君子) manner. I have thus learnt from them also in this connection on the journey towards the truth pursuit while endeavoring to become jun-zi. As I believe that such engaging discussion of their works would be one most philosophically interesting and rewarding way to their significant philosophy scholarship, I intend to constructively present my philosophical critique of their approach while learning from them. 
speakers do with language in its situated uses (speech acts). More generally, or methodologically speaking and in view of its "metaphysical" base (in a sense to be addressed below) if any, a "pragmatic" perspective points to and capture the humanaction-process-involved becoming aspect or layer (if any) of an object of study (in the human world). ${ }^{8}$ Indeed, as a way to look at the human-action-process-involved becoming aspect of an object of study, a "pragmatic" perspective per se is a more or less innocent or neutral way to the extent that any agent is entitled or event expected to take her "pragmatic" perspective if she intends to focus on the action-processinvolved becoming aspect or layer (if any) of the object for a certain purpose, and if the object does possess its action-process-involved becoming aspect or layer, the addressed "pragmatic" perspective (as a token of the "pragmatic" perspective type) would be "eligible" (if otherwise, it would be "ineligible"). In so saying, I contend that the merit, status, and function of a methodological perspective per se can be evaluated independently of certain methodological guiding principles that the agent might presuppose in her actual application of the perspective. In contrast, pragmatism or the pragmatist indicates a more theoretically-loaded philosophical attitude or (methodological) guiding principle regarding how to look at the status of the "pragmatic" perspective and its relationship with other (eligible) perspectives to look at things. In this way, one can take a "pragmatic" perspective without necessarily subscribing to a "pragmatist" philosophical position that renders the "pragmatic" perspective par excellence or absolutely superior to the other (eligible) perspectives.

Now, with the foregoing clarification and substantial distinctions, let me explain what is at issue and where the addressed agreements and disagreements are located. Actually, partially because I would like to have a more complete understanding of the Hall-Ames approach and partially because I intend to have more sufficient theoretic elaboration, and more test cases for the explanatory potency, of the constructiveengagement strategy, I had not explicitly and directly made my evaluative remarks on the Hall-Ames "pragmatist" approach since I first read some of their relevant writings around two decades ago until last year when I needed to write an piece on the methodological issue in studies of Chinese philosophy in cross-tradition engagement. It includes a brief evaluative passage presenting my basic attitude towards the HallAmes "pragmatist" approach, which is cited in Dr. Sun's article as follows:

[T]he Hall/Ames style pragmatic approach as a whole can be refined into its pragmatic "perspective" dimension and its foregoing pragmatist "guiding-principle dimension; its

\footnotetext{
${ }^{8}$ See relevant characterizations and illustration in Appendix 4. It is noted that, to this extent and in this connection, the distinction between the "pragmatic" and the "semantic" (understood in a broad sense of 'semantic' regarding the relation between a linguistic expression/a perspective and an extralinguistic/extra-perspective object) seems blurring; however, insofar as the human-action-processinvolved "becoming" aspect of the human world is fundamentally part of (rather than exhausting) this natural world as a whole to which the most fundamental semantic relation points, the "pragmatic" is fundamentally explained, and thus needs to be understood, in the terms of the "semantic". In this sense and to this extent, such a "pragmatic" perspective needs to be regulated and guided by the fundamental "same-natural-world" norm and the "way-things-are-capturing" norm in any reflective/intellectual pursuit of "how things are", a point as explained in Appendix 4.
} 
pragmatic perspective per se can be "eligible" whenever there are such "pragmatic" aspects of objects of study which certain "pragmatic" perspectives are in need to point to and capture; however, an indiscriminate "pragmatist" guiding principle identified above can be "inadequate" because it does not do justice to other "eligible" perspectives but celebrates the pragmatic perspective only. In this sense, and to this extent, the constructive-engagement strategy can do justice to the "pragmatic" methodological perspective while explaining why and in which connections an indiscriminate "pragmatist" methodological guiding principle needs to be regulated. (Mou 2018, 12)

Then, in a more specific engaging setting, I elaborate the foregoing general point through examining the Hall-Ames "pragmatist" approach to the issue of the relation between tian/tian-ming and human morality (Mou 2019, Sections 5.1 and 5.5). This case analysis not merely illustrates my general evaluation line but also explains certain basic norms in cross-tradition philosophical engagement directly relevant to my discussion here. (Its main content is thus is given in Appendix 4.) In the following, I give a further explanation of my basic engaging line in view of Dr. Sun's characterization of the two approaches in several connections.

As briefly mentioned above, in my view, the methodological part of the HallAmes "pragmatist" approach as a whole can be refined into its two dimensions: i.e., its "pragmatic-perspective" dimension and its "pragmatist-guiding-principle" dimension, which can be presented in the subsequent more explicit terms Its "pragmatic-perspective" dimension (if my understanding of the relevant resources in their approach is correct) can be viewed as consisting of a range of "pragmatic" perspectives (types) as follows.

(1) The "becoming"-aspect-concerned "pragmatic" perspective regarding the issue of the concentrated identity of an object of study in the human world as part of this natural world (or the human "immanent-phenomenon" world, in the Hall-Ames terms), ${ }^{9}$ which points to its human-action-process-involved "becoming" aspect ('becoming' aspect for short). ${ }^{10}$ It is noted that, generally speaking (even for the human world), unless an object of study goes with the "becoming" aspect only, there are other (eligible) perspectives that point to and capture some other aspects or layers of the object. Among various types of "pragmatic" perspectives, this type of "pragmatic" perspectives would be rendered primary to this extent: it directly addresses the "metaphysical" basis of various types of relevant "pragmatic"

\footnotetext{
${ }^{9}$ See the relevant explanation of this in Appendix 4.

${ }^{10}$ In this context in which the Hall-Ames-style "pragmatist" approach is under examination, I would render suitable and fair to label the aspect or layer of an object of study that is conducive or up to a "pragmatic" treatment the 'becoming' aspect, as the terminology 'becoming' is what Hall and Ames themselves prefer in the "pragmatic" discourse. In his memorial article for David Hall, Ames states that "[a]s a philosopher, [Hall] was a self-confessed 'pragmatist,' where the defining characteristic of a pragmatist as he understood it is to become your best thoughts. For David, there was and is real comfort and indeed even a religious awe in the recognition that assuming the form of one kind of thing gives way to becoming another in a ceaseless adventure. His counsel for us, like that of the Toyota salesman, would be: enjoy the ride" (Ames 2002, 277; my italics for emphasis).
} 
perspectives. In my view, in contrast to some other "pragmatist" approaches, it is one merit of the Hall-Ames "pragmatist" approach to explicitly seek and emphasize the "metaphysical" basis of various types of "pragmatic" perspectives through stressing the "becoming"-aspect-concerned "pragmatic" perspective when looking at the surrounding world in this way; the Hall-Ames approach thus actually renders primary the "becoming"-aspect-concerned "pragmatic" perspective. [As explained in Appendix 4, the Hall-Ames approach's "pragmatic" perspective in this connection (to capture the "becoming" way things are in what they call "phenomenal" world as part of this natural world) essentially presupposes one fundamental common norm that is shared, and needs to be observed as one guiding norm, in any reflective and intellectual pursuit of "how things are", i.e., "the way-things-are-capturing" norm, whether or not it would be recognized by one or both sides of the debate.]

(2) The criterion-concerned "pragmatic" perspective regarding the issue of how to identify and specify a criterion for the human-action-process-involved solution to a problem or concern in view of its effectiveness. It is noted that there are various criterion perspectives that point to distinct aspects of the issue of how to identify and specify a criterion by means of which to tell if a solution is adequate for the sake of approaching a problem; the criterion-concerned "pragmatic" perspective points to the "effectiveness-seeking" concerned aspect of the issue, which is related and sensitive to the "becoming"-aspect of an object of study (in the human world) to the extent that any treatment that is sensitive to the changing/becoming aspect of the object would be more effective than otherwise; there are other perspectives that point to some other aspects, such as the coherence concerned aspect, the piecemeal-correspondencecapturing concerned aspect, the holistic-correspondence-capturing concerned aspect , etc. The rationale for this is related to the aforementioned "way-thing-are-capturing" norm: if the way of an object of study goes with, say, its own "coherence" layer up to a coherence criterion, its own "specific-piece-by-piece-attribute-constitution" layer up to a piecemeal-correspondence criterion, its own "holistic-constitution" layer up to a holistic-correspondence criterion, as well as its own "becoming" layer up to a "pragmatic" criterion, then all these criteria (as distinct perspectives) would be eligible and eventually complementary.

(3) The relevant/irrelevant-element-identifying "pragmatic" perspective regarding the issue of how to identify and select relevant contributing elements to a solution for approaching a problem when in focus on whether it is effective or works. It is noted that, methodologically speaking, there are various distinct perspectives regarding how to identify relevant and irrelevant elements to a solution for approaching a problem; the addressed "pragmatic" perspective in this connection is identified in "pragmatic" terms for this reason: it is a kind of "bottom-up" "pragmatic" approach (with no current "top-down" theoretic guidance, at least technically speaking when one focuses on the "effectiveness"-seeking aspect of the issue), emphasizing or focusing on which elements can contribute to working or being effective for the sake of resolving a problem (given a certain identity of the problem). Such a type of "pragmatic" perspective is what Dr. Sun refers to when characterizing the Hall-Ames approach in this way: without resorting to "the common philosophical theorization 
between the two different traditions" (Sun 2019, 127), “...the differences and similarities in the metaphysical background and the whole philosophical system are laid aside" (Sun 2019, 128).

The first type of "pragmatic" perspective, as indicated above, would be rendered primary while the other types secondary to this extent: the former directly addresses the "metaphysical" basis of the latter regarding the human-action-process-involved "becoming" aspect of the human world; the understanding of the latter would be eventually based on the understanding of the former (as partially addressed above).

With the explanatory resources concerning the distinctions between (eligible vs. ineligible) methodological perspectives and methodological (adequate vs. inadequate) guiding principles, as explained in Appendix 1, we can see that the merit, status, and function of a methodological perspective per se can be evaluated independently of certain methodological guiding principles that the agent might presuppose in her actual application of the perspective. From the "constructive engagement" vantage point, the "pragmatic"-perspective dimension of the Hall-Ames "pragmatist" approach makes two significant contributions in studies of Chinese philosophy and comparative Chinese-Western philosophy: first, generally speaking and methodologically speaking, the Hall-Ames approach provides a variety of effective "pragmatic" perspective resources; second, specifically speaking, the Hall-Ames approach applies these "pragmatic" perspectives in examining a range of significant issues in Chinese philosophy and comparative Chinese-Western philosophy and has significantly enhanced our understanding and treatment of the issues at least regarding those aspects and layers of them that are "eligibly" up to the treatments of these "pragmatic" perspectives, as emphasized before. The constructive engagement strategy, as a meta-methodological approach in doing philosophy comparatively, is open-ended and inclusive for all eligible methodological perspectives (including all eligible "pragmatic" perspectives), as tokens of their types, regarding various jointlyconcerned philosophical issues (either substantial or methodological ones).

Now, as far as the "guiding-principle" dimension of the Hall-Ames "pragmatist" approach is concerned, the constructive-engagement strategy does share with it some central ideas concerning the role of comparative philosophy in philosophy and the possibility of the reflective engagement between distinct resources from different philosophical traditions, as shown by those passages that Dr. Sun cited in his article: among others, both emphasize the important role played by comparative philosophy; both stress the mutual enhancement of different traditions through cross-tradition engagement; both agree that one goal of such cross-tradition engagement is to seek solutions to significant problems in philosophy. The Hall-Ames approach and the constructive engagement approach are in accordance in these connections.

Nevertheless, on the other hands, in my view, there are several major disagreements between the Hall-Ames "pragmatist" approach and the constructiveengagement strategy at the guiding principle level regarding how to look at the status of the "pragmatic" perspective (a collection of various types of "pragmatic" perspectives) and their relation to other (eligible) methodological perspectives. First, what really distinguishes the Hall-Ames "pragmatist" approach as a whole from other 
non-"pragmatist" approaches [whether or not, and no matter how, the latter approaches also explicitly include this or/and that type(s) of "pragmatic" perspectives at their "perspective" dimensions] lies primarily in this at the guiding-principle level: as far as the status of the "pragmatic" perspective and its relation to the other approaches are concerned, the Hall-Ames approach treats the aforementioned primary type of "pragmatic" perspectives par excellence or indiscriminately superior to the other perspectives (types), as Hall and Ames advocates "pragmatism and historicism" whose basic point is a sweeping "pragmatist" guiding principle that "in the area of comparative studies, philosophical theorizing should be replaced by more concrete, praxix-oriented endeavors" (Hall and Ames 1995, xxi). On this engaging front, I have already explained why, generally speaking, a methodological guiding principle that celebrates only one perspective is problematic both in general theoretic terms (see Appendix 3) and through a specific case analysis concerning the Hall-Ames approach in treating the issue of tian/tian-ming as given in section 1 of Appendix 4.

Second, what distinguishes the Hall-Ames "pragmatist" approach from the constructive-engagement approach also lies in this: at the guiding-principle level, the Hall-Ames approach denies the jointly-concerned character of the "common" issues or problems between different philosophical traditions but "isolate a particular problem within" one tradition (Hall and Ames 1987, 5; my italics), as correctly highlighted by Dr. Sun; in this way, given an object of study that is presented in terms of a certain perspective in one tradition, it would treat as "extraneous" to the object of study (as explored in that tradition) those distinct perspectives (together with their associated conceptual resources) from other different traditions (cf., Hall and Ames 1995, xxi), as they really talk about the same object though in distinct perspective in focus on the distinct aspects or layers of the object. in contrast, the constructiveengagement approach not merely recognizes but emphasizes the jointly-concerned character of a range of issues and problems in cross-tradition philosophical engagement; it stresses the fact to the effect that people (ordinary or reflective agents), within one tradition or from different traditions, can talk about the same object differently (rather than thus talking about different objects) with distinct perspectives in focus on distinct aspects/layers of the object which are related and complementary rather than "extraneous" to each other. Actually, the disagreement in this connection is intrinsically related to the aforementioned disagreement about how to look at the due relationship between the "pragmatic" perspective and other (eligible) methodological perspectives: if there is no jointly-concerned object of study (such as this jointly-designated and jointly-concerned natural world), then we cannot talk about this "same" object (i.e., the same referential meanings) differently, and thus these distinct perspectives in focus on distinct aspects of the object would be treated as "extraneous" instead of being intrinsically related and complementary; actually, given an object of study, this jointly-concerned object of study constitutes the fundamentally shared "referential" meaning of the linguistic expressions of the distinct perspectives that point to distinct aspects of the same object; among others, this jointly-designated and jointly-concerned natural world constitutes the most basic "referential" meaning, which is indeed "neutral" in the following two senses: first, it 
is what the most prominent, widespread and fundamental "underlying agreement" (in Donald Davidson's terms) ${ }^{11}$ is about; second, it is the "same" object that people can talk about differently. As for how people can designate and talk about the same object (as the same referent, i.e., the same referential meaning) differently (with distinct perspectives in focus on distinct aspects of the object), not merely we can understand this based on our pre-theoretic understanding of the "double reference" phenomenon of the basic language employment [i.e., when saying something about an object, a speaker talks about (primarily refers to) the object as a whole while at the same time pointing to (secondarily referring to) a certain specific aspect of the object relative or sensitive to what is sought]; ${ }^{12}$ there is also the rich literature in contemporary philosophy of language on how speakers can designate the same referent via speakers' (distinct) communication links via the Fregean vs. Kripkean debate. ${ }^{13}$

Third, as for how to look at the status and nature of the "effective"-criterionconcerned "pragmatic" perspective, at its guiding-principle level, the Hall-Ames approach includes its "pragmatist" theory of truth that actually identifies truth nature (what truth is) in terms of truth criterion [by means of which to judge whether a statement or solution is (probably) true]; it also treats the "effective"-criterionconcerned "pragmatic" perspective as the exclusively eligible criterion or means by which to judge whether a (solution) statement/account is (probably) true or false. In this way, there are two major difficulties with the Hall-Ames approach's "pragmatist" theory of "truth" at the guiding principle level: (1) it places the "effective"-criterionconcerned "pragmatic" perspective in the truth-nature project where it does not really belong; (2) it treats the "effective"-criterion-concerned "pragmatic" perspective as the exclusively eligible criterion when in fact it is not. In contrast, the constructiveengagement strategy's approach in this connection is this: (1) it treats people's pretheoretic "way-things-are-capturing" understanding of truth as one normative basis for the philosophical concern with truth and distinguishes the "truth-nature" dimension of the philosophical issue of truth from its "justification" dimension: the latter is concerned with a criterion of truth that gives us a test or evidence by means of which the (probable) truth or falsity of a statement can be judged; (2) the "effective"-criterion-concerned "pragmatic" perspective is only one, instead of the exclusive one, among a number of criteria by means of which we can judge whether a statement is (probably) true or false. ${ }^{14}$

Fourth, as for relevant/irrelevant-element-identifying "pragmatic" perspective regarding the agent's choice of the compositional and surrounding elements of a

\footnotetext{
${ }^{11}$ Cf., Davidson 2001, v.

${ }^{12}$ For my discussion of the "double reference" phenomenon of people's basic language employment and how it bears on our understanding of the identity of an object of study, see Mou 2018a.

${ }^{13}$ For a recent clearly written boo on the puzzles of reference in view of most recent scholarship on the issue, sse Capplelen \& Dever 2018.

${ }^{14}$ As I have a separate comprehensive examination of the issue in another writing (Mou 2019), I do not say more here on this but refer the interested reader to my detailed discussion there (especially in Section 1.2, Section 1.3 and Section 5.4.3).
} 
solution to a problem, at the guiding principle level, the Hall-Ames approach actually treats it as the exclusive perspective to the following extent: (1) without recognizing the jointly-concerned nature of the problem, it would render a solution from one tradition "extraneous" and "external" (rather than internal) to the problem in another tradition; in this way, there is no room for the solution and the problem being intrinsically or internally related, and there is no need for a "top-down" theoretic guidance and coordination for the sake of capturing the connection between the target solution form one tradition and the problem in another tradition and between the target solution in one tradition and some other relevant solutions from some other tradition(s) (including the tradition where the addressed problem was initially identified); (2) rather, what are in need are only just "external" trial and test at the practical level for the sake of seeking effectiveness and having the solution working; (3) in this way, what counts as relevant or irrelevant is expected to be identified and looked at from a "pragmatic" perspective only, instead of some other perspectives else in this connection.

In contrast, the constructive engagement strategy treats the "pragmatic" perspective in this connection as one eligible perspective, but not the exclusive one, when there are some other contributing perspectives to identifying what count as relevant or irrelevant to a solution to a problem. (1) With recognizing the jointlyconcerned nature of the problem, it would not render a solution from one tradition "extraneous" and "external" but "internal" to a jointly-concerned issue or problem that might be initially identified and prominently given in another tradition; the solution and the problem are thus treated as being intrinsically or internally related; their genuine relation needs to be identified through a "top-down" theoretic guidance and coordination that would guide us to capturing the (underlying) connections between the target solution form one tradition and the problem in another tradition and between the target solution in one tradition and some other relevant solutions from some other tradition(s) (including the tradition where the addressed problem was initially identified); (2) therefore, what are in need are not only "external" trial and test at the practical level for the sake of working and effective; (3) in this way, what counts as relevant or irrelevant is expected to be identified and specified not merely from a "pragmatic" perspective alone, but also from some other perspectives else in this connection.

As indicated before, one can take a "pragmatic" perspective without necessarily subscribing to a certain "pragmatist" philosophical position that would render the "pragmatic" perspective par excellence or absolutely superior to the other (eligible) perspectives. ${ }^{15}$ What the constructive-engagement strategy disagrees to are the

\footnotetext{
${ }^{15}$ Actually, in some of my own previous writings, I myself also take a "pragmatic" perspective in looking at some issues under examination, sensitive to the need and focus of these writings. I take a certain "pragmatic" perspective to focus on the action-process becoming aspect/layer of the classical Daoist approach to the issue of human morality in Mou 1997 and 2002, as highlighted by the titles of these writings (i.e., "A Pragmatic Insight Regarding Morality: From a Comparative Perspective" and "Moral Rules and Moral Experience: A Comparative Analysis of Dewey and Laozi on Morality"),
} 
aforementioned pragmatist ideas of the Hall-Ames "pragmatist" approach at its guiding-principle dimension, rather than the "pragmatic"-perspective resources per se at its "perspective" dimension. With the foregoing analysis of the Hall-Ames "pragmatist" approach and the explanation of where its engaging points are located from the constructive-engagement point of view, I would be thus in a better position to look at Dr. Sun's "synthetic" approach that sets out to combine parts of the two approaches that he would render constructive and effective.

\subsection{A METHODOLOGICAL REFLECTION ON SUN WEI'S "SYNTHETIC" APPROACH IN TREATING ARISTOTLE'S AND XUN ZI'S ACCOUNTS}

Dr. Sun suggests an interesting "synthetic" approach that sets out to incorporate those parts from the Hall-Ames approach and the constructive-engagement strategy that he renders reasonable. Dr. Sun's strategy is this: he first highlights the major relevant points of the two approaches to his "synthetic" approach; and then he illustrates his approach through applying it to carrying out a comparative case study of how Xun Zi's Dao-resources can significantly contribute to resolving the jointly-concerned problem raised by Aristotle's Eudaimonia approach to the issue of human happiness. Dr. Sun's comparative case analysis per se is an excellent substantial exploration of how the two thinkers' relevant resources to the issue can jointly contribute to our understanding and treatment of the issue. In the following, in view of the purpose of this writing as a whole, I focus on the methodological dimension of Dr. Sun's approach, rather than his substantial view on the jointly-concerned substantial issue. That is, I give a methodological reflective on his "synthetic" approach in treating Aristotle and Xun Zi's accounts in view of the explanatory potency of the constructive-engagement strategy.

If my understanding of Dr. Sun's approach is correct, he agrees with the constructive-engagement strategy while disagreeing with the Hall-Ames approach in two major connections: first, he recognizes that there are jointly-concerned problems among different traditions; second, he agrees that "we might not neglect the philosophical theorization in the comparative philosophy" (Sun 2019, 141). With these two major points in view, he highlights his methodological treatment this way:

After finding the jointly concerned problem, we can find the practical solutions to the problem. In terms of the understanding of Xun Zi's Dao, we could find that the way for attaining Dao is virtuous activities, which could be compared to the virtuous activities in Aristotle. In the next step, we find that the crucial phase in attaining Dao is " $x u, y i$ and jing", which is quite similar to the process of " $\theta \varepsilon \omega \rho \iota \alpha$ " in Aristotle. In this sense, we could understand the relationship among the virtuous activities, " $\theta \varepsilon \omega \rho l \alpha "$ and eudemonia by employing the understandings of Xun Zi's virtuous activities, " $x u$, yi and jing” and

though I do not subscribe to the "pragmatist" guiding principle that would indiscriminately render the "pragmatic" perspective absolutely superior to other perspectives. 
Dao. Although there are quite a lot of historical and philosophical differences between Xun Zi and Aristotle's philosophy, it is in the jointly concerned problem that Xun Zi's philosophy could provide a solution for the dispute of inclusivism and intellectualism in understanding Aristotle. (Sun 2019, 144; italics of those non-transliteration English terms are mine for emphasis.)

I have five commentary remarks on the methodological dimension of Dr. Sun's comparative case study. First, several crucial elements that make the addressed "jointly-concerned" character possible lie in these: both Aristotle and Xun Zi address the same human world that is part of this common natural world; this fundamental "common" connection renders the "virtuous activities" addressed by Xun Zi and the "virtuous activities in Aristotle" kindred in their fundamental nature; this fundamental "common" connection also renders the crucial phase in attaining Dao, i.e., " $x u$, yi and jing" regarding the relationship among the virtuous activities, as specified by Dr. Sun, and the process of " $\theta \varepsilon \omega \rho l \alpha$ " in Aristotle's account kindred in their treatment strategy. The foregoing "jointly-concerned" character would thus provide the rationale for how both sides can learn from each other and make their joint contribution to the addressed jointly-concerned issue in an engaging way.

Second, it is noted that Dr. Sun uses the term 'practical' to describe the solution that he addresses in this specific case and that, more generally speaking, he uses 'pragmatic' to label the Hall-Ames "pragmatist" approach; given the distinction between the "pragmatic" perspective and the "pragmatist" guiding principle and given the previously analyzed "pragmatist" way in which, at its "guiding-principle" dimension, the Hall-Ames approach looks at the status of the "pragmatic" perspective in its "perspective" dimension, it seems unclear exactly whether Dr. Sun accepts only the "pragmatic" perspective in the Hall-Ames approach or also its "pragmatist" guiding principle regarding the status of the "pragmatic" perspective. Nevertheless, based on Dr. Sun's specification of the intrinsic connection between the jointlyconcerned problem and the "practical" solution in terms of "After finding the jointly concerned problem, we can find the practical solutions", I can say that he does not subscribe to the Hall-Ames approach's "pragmatist" guiding principle regarding the status of the "pragmatic" perspective: as explained before, the primary reason for the Hall-Ames approach renders the "pragmatic" perspective par excellence is this: it denies the jointly-concerned character of the "common" issues or problems between different philosophical traditions but "isolate a particular problem within" one tradition; if there is no jointly-concerned object of study (such as a jointly-concerned issue and this jointly-designated and jointly-concerned natural world), then we cannot talk about this "same" object (i.e., the same referential meanings) differently, and thus these distinct perspectives in focus on distinct aspects of the object would be treated as "extraneous" and irrelevant instead of being intrinsically related and complementary regarding the jointly-concerned issue. Now, as Dr. Sun explicitly disagrees to the Hall-Ames approach's denial of the jointly-concerned character of the addressed problem, based on the principle of charity in philosophical interpretation, I contend that Dr. Sun's foregoing position at least implies that he 
disagrees to the Hall-Ames approach's "pragmatist" position regarding the status of the "pragmatic" perspective, though he endorses the "pragmatic" perspective.

Third, more specifically speaking, the types of "pragmatic" perspectives that Dr. Sun endorses and applies in treating the current jointly-concerned substantial issue under examination are two distinct but closely related types of "pragmatic" (or "practical") perspectives respectively regarding two related methodological issues (they are implicitly associated with the jointly-concerned substantial issue under his examination): (1) as suggested by his cited statement "it is more practical to test or experimental thinking", the criterion-concerned "pragmatic" perspective regarding the issue of how to identify and specify a criterion for the human-action-processinvolved solution to a problem in view of its practical effectiveness; (2) as suggested by his statement in delivering the Hall-Ames approach's "pragmatic" point "the goal...is to find a practical solution to a particular philosophical problem in one tradition, while the differences and similarities in the metaphysical background and the whole philosophical system are laid aside", the relevant/irrelevant-elementidentifying "pragmatic" perspective regarding the issue of how to identify and select relevant contributing elements to a solution for resolving a problem when in focus on whether it is effective. Because of the preceding points of Dr. Sun's approach (i.e., recognizing the jointly-concerned character of the addressed problem that might be initially identified in one tradition in an explicit but distinct way, and disagreeing to the Hall-Ames approach's "pragmatist" position regarding the status of the "pragmatic" perspective), I think that Dr. Sun does not reject other non-pragmatic perspectives regarding the two issues: (1) the issue of how to identify and specify a criterion for the human-action-process-involved solution to a problem or concern; (2) the issue of how to identify and select relevant contributing elements and disregard irrelevant elements to a solution for resolving a problem. He would thus render complementary the "pragmatic" perspective and other non-pragmatic perspectives in treating one jointly-concerned issue for which these distinct perspectives are eligible.

Fourth, it is also noted that, in a specific project with a certain purpose and focus, one can focus on how the resources of one thinker in one tradition (in either ancient or modern times) can provide a solution to a jointly-concerned issue that is prominently raised by another thinker in another tradition in some distinct way; this pattern of treatment per se is not intrinsically associated with the "pragmatic" character but also adopted by many specific projects in the direction of the constructive-engagement strategy. Indeed, the constructive engagement strategic goal and methodology can be manifested and implemented in various distinct ways, with distinct emphases and at different levels, and sensitive to the needs and purposes of specific research projects, instead of being restricted to one fixed pattern or merely one level. Surely, an ideal situation would be that engaging parties, like conversation partners on the same occasion, directly talk with each other and learn from each other at each of the involved levels of engagement while addressing various distinct aspects of their subject of joint concern. However, more often engaging parties learn from each other and make joint contributions through their respective constructive impacts or roles. They enhance our understandings and treatments of distinct aspects of an 
issue of joint concern, sometimes at different levels of engagement (say, the methodological-guiding-principle level, the methodological-perspective level, or the methodological-instrument level). Furthermore, sensitive to the purpose and need of a project in contemporary studies of a philosophical tradition, one can effectively start with a contemporary or ancient (thinker's) account of an issue in one tradition and then focus on exploring how some contemporary or ancient thinker's view in another tradition can engage with the former at one or more levels in treating some aspect of that issue, ${ }^{16}$ at the same time, one can also address the former figure's contribution at another level in treating some other aspect of the same issue - one can thus have both parties jointly contribute to a more promising new account in a broader framework that integrally includes reasonable and eligible elements from both sides. ${ }^{17}$

Fifth, if my understanding and analysis of Dr. Sun's approach in the foregoing connections are correct, I would like to say that, methodologically speaking, Dr. Sun's "synthetic" approach is much closer to, or even might be viewed as a variant of, the constructive-engagement strategy, rather than the Hall-Ames "pragmatist" approach, to this extent: the constructive-engagement strategy as a metamethodological framework with its explanatory resources and with its open-ended character is to include these addressed resources concerning methodological perspectives and methodological guiding principles in Dr. Sun's approach under examination. More specifically speaking, (1) the constructive-engagement strategy explicitly includes those meta-methodological guiding-principle ideas, as explained in the engaging setting with the Hall-Ames approach in Section 3.1, which I believe Dr. Sun's approach might also share; (2) it firmly holds a thoroughly open-ended and inclusive attitude towards all eligible (and thus fundamentally complementary) methodological perspectives (including all eligible "pragmatic" perspectives), as tokens of their types, regarding various jointly-concerned philosophical issues (either substantial or methodological ones) and thus implicitly includes them. ${ }^{18}$ However, I need to be cautious at this point: for one thing, as the reader can see, some parts of my evaluative comments on Dr. Sun's "synthetic" approach are my interpretative remarks, instead of his own words; for another thing, Dr. Sun's discussion as made in his paper here does not (or is not intended by him to) address all of the substantial points concerning methodology in the Hall-Ames approach and the constructiveengagement strategy that are either explicitly made or implicitly prescribed in the two approaches, ${ }^{19}$ to this extent, my evaluation of his account is also incomplete.

\footnotetext{
${ }^{16}$ For example, in one of my own specific projects (Mou 2015), I focus on how Zhuang Zi's resources can contribute to the jointly-concerned issue raised by Quine in his naturalized epistemology.

${ }^{17}$ For example, the constructive-engagement strategy is taken in such a way in the collective research project "Davidson's philosophy and Chinese philosophy". For its research outcome, see Mou 2006.

${ }_{18}$ As indicated in Appendix 1, a perspective type cannot be indiscriminately rendered eligible regarding all of jointly-concerned objects of study; whether or not a specific token of a perspective type regarding one specific object of study is eligible is determined by whether it points to and captures some aspect that is really possessed by the object. This is another sense in which a general methodological framework, if open-ended, can only implicitly include all eligible specific perspectives.

${ }^{19}$ for example, Dr. Sun does not address their distinct ways of looking at the nature of truth that significantly bear on their central ideas at their respective guiding-principle dimensions. In the case of
} 


\section{APPENDIX 1: \\ PRELIMINARY CONCEPTUAL RESOURCES AND DISTINCTIONS OF CONSTRUCTIVE-ENGAGEMENT STRATEGY ${ }^{20}$}

In this part, in an accessible way, I introduce some preliminary explanatory resources and conceptual distinctions in need for two purposes: first, to have a refined understanding and characterization of some methodological concepts and their related distinctions (among others, 'methodological perspectives' and 'methodological guiding principles'); second, to more clearly and accurately characterize distinct dimensions of methodological approaches in philosophical inquiries and thus some related methodological points of the constructiveengagement strategy.

Given that the term "methodological approach" means a way responding to how to approach an object of study, the term is a generic term to mean a number of methodological ways. There are three distinct but related ways in which one can approach an object of study, which together constitute three distinct dimensions of a methodological approach as a whole. That is, in the context of philosophical inquiries, generally speaking, the notion of methodological approach can, and needs to, be refined into three distinct but related notions of methodological ways for the sake of adequately characterizing three distinct but somehow related methodological ways in philosophical inquiries, i.e., those of methodological perspective (or perspective method), methodological instrument (or instrumental method), and methodological guiding principle (or guiding-principle method), as specified below. (1) A methodological perspective is a way of approaching an object of $s_{t u d y}{ }^{21}$ and is intended to point to or focus on a certain aspect of the object and capture or explain that aspect in terms of the characteristics of that aspect, with its minimal metaphysical commitment that the object does possess that aspect. There are two important distinctions concerning methodological perspectives. First, there is the distinction between eligible and ineligible methodological perspectives. An eligible methodological perspective points to and captures a certain aspect that is actually possessed by the object, while an ineligible one does otherwise. Second, there is the distinction between a methodological-perspective simplex and a methodological-perspective complex. A simplex is a single discernible methodological perspective, and a complex is either a combination of simplexes ("multiple perspective complex") or an association of one perspective (simplex) with a certain methodological guiding principle ("guiding-principle-associated perspective complex"). By "perspective" below I mean a methodological perspective simplex unless otherwise indicated. It is also noted that a perspective type, generally speaking, cannot be indiscriminately rendered eligible regarding all of jointly-concerned objects of study; whether or not a specific token of a

the constructive-engagement strategy, its recognizing the jointly-concerned philosophical issues and its addressed "same-object-recognizing" norm presuppose people's pre-theoretic “way-things-arecapturing" understanding of truth that is treated as one normative basis for the philosophical concern with truth (cf., Mou 2019, Chapter 1).

${ }^{20}$ An early version of the material of Appendix 1 was first presented in Mou 2001b.

${ }^{21}$ As indicated before, the identity of a (genuine) object of study in philosophy is understood broadly: as a naturally produced object in physical reality, a constructed object in social reality, a "linguistic" object (such as a word), an abstract object in philosophical theory, or an "issue" object in philosophy (such as the philosophical issue of truth with its distinct but related dimensions), referentially accessible and critically communicable among participants in philosophical dialogue. 
certain perspective type regarding one specific object of study is eligible depends on whether or not it really points to and captures some aspect or layer of the object of study. ${ }^{22}$

(2) A methodological instrument is a way in which to implement, or give tools to realize, a certain methodological perspective. Methodological instruments are largely neutral in the sense that they can serve to implement different methodological perspectives, though there is still the distinction between more and less effective methodological instruments with regard to a given methodological perspective.

(3) A methodological guiding principle regulates and guides a certain methodological perspective (or perspectives) with regard to an object of study. Explicitly assumed or implicitly presupposed by the agent, it implicitly guides and regulates how the perspective should be evaluated and used and contributes to the establishment of its desiderata (especially, the purpose and focus that it is to serve). There are adequate and inadequate methodological guiding principles. For example, in looking at the relation between the agent's current perspective in treating an object of study and other eligible perspectives (if any), a methodological guiding principle is considered adequate (in regard to recognizing perspective eligibility) when it allows in other eligible perspectives to complement the application of the current perspective and thus has the agent realize that these eligible perspectives do separately capture distinct aspects of the object and thus can jointly make complementary contributions to capturing the way the object is. It is considered inadequate if otherwise.

There are three morals we can draw about the relations between the three methodological things. (1) The merit, status, and function of a methodological perspective per se can be evaluated independently of certain methodological guiding principles that the agent might presuppose in her actual application of the perspective. (2) One's reflective practice per se of taking a certain methodological perspective as a working perspective to focus on a certain aspect of the object implies neither that one loses sight of other genuine aspects of the object nor that one ignores or rejects other eligible perspectives in one's background thinking. (3) On the other hand, it does matter whether one's taking a certain methodological perspective is regulated by an adequate or inadequate guiding principle, especially for the sake of constructive engagement of seemingly competing approaches, for an inadequate guiding principle will close out and dismiss certain eligible perspectives in an inadequate way.

\section{APPENDIX 2:}

TWO METHODOLOGICAL EMPHASES OF CONSTRUCTIVE-ENGAGEMENT STRATEGY ${ }^{23}$

One of the major methodological emphases in the constructive-engagement strategy is on (appropriate) philosophical interpretation ${ }^{24}$ of a thinker's texts under examination instead of

\footnotetext{
${ }^{22}$ Whether or not there can be an eligible perspective type whose designated "aspect" would be really possessed by any objects of study is largely a metaphysical issue which I do not intend to pursue here.

${ }^{23}$ The basic ideas presented in Appendix 2 have been presented in some previous publications of the author (the version here is an excerpt from section 2 of Mou 2018b.

${ }^{24}$ Here the term "interpretation" is employed in a neutral and straightforward sense as specified here (in terms of elaborating and understanding with a certain focus and a certain reflective purpose other than mere historical description), rather than in some philosophical-doctrine-loaded sense as often delivered by the term 'hermeneutics' (and its cognate 'hermeneutic'), which is taken to primarily refer to Hans-Georg Gadamer's doctrine in the literature; for this consideration, I intentionally avoid using
} 
mere historical description. It is noted that, generally speaking, the primary purpose of this methodological orientation is to enhance our understanding of a thinker's texts and elaborate their due implications of philosophical significance for the sake of philosophical exploration (say, their contribution to the contemporary development of philosophy on a certain philosophical issue) via relevant effective conceptual and explanatory resources, whether or not those resources were actually used by the thinker herself. It is clear that a purely historical approach does not fit here: to elaborate and understand the thought of the thinker's texts does not amount to figuring out exactly what resources the thinker actually used and exactly what explicit ideas she actually thought of; instead, such interpretation and understanding might include the interpreter's elaboration of the points of the thinker's texts including the subtle implications of the points, which might not have been explicitly considered by the thinker herself, and/or the interpreter's representation of the thinker's point in clearer and more coherent terms or in a more philosophically interesting way, which the thinker herself might have not actually adopted. In both cases, given a thinker's ideas (in one tradition or account) under interpretation, some effective conceptual and explanatory resources well developed in another tradition or in contemporary philosophy can be consciously employed to enhance our understanding of, and to elaborate, the thinker's ideas.

In this way, the use of relevant "external" resources might really enhance our understanding of a thinker's ideas or clarify some original unclear or confusing expression of her ideas. Consequently, the endeavor per se of using external resources in this orientation is not automatically inappropriate, as it would be in the merely historical orientation. Note that when those explanatory and conceptual resources are used, they are not intended to assign the same degree of articulated systematization and of mastering some conceptual and explanatory resources to an ancient thinker but to enhance our understanding of her ideas delivered in the text. For this interpretative purpose, it is not merely legitimate but beneficial to employ more explicit or clearer conceptual resources to elaborate some otherwise implicit and hidden things (say, coherence and connectedness) in a thinker's ideas that was sometimes less clearly delivered or expressed in some paradoxical way for lack of those contemporary explanatory and conceptual resources that are unavailable to the ancient thinker but now available to us. ${ }^{25}$ It is also noted that, when a thinker's line of thought and her ideas lack in articulated systematicity in their language expressions, that does not amount to saying that the thinker's line of thought and her ideas per se do not have (implicit and hidden) coherence and connectedness deep in the thinker's ideas. Consequently, we cannot rely merely on this lack of articulated systematicity in language expression and therefore judge that the thinker's text itself is not a philosophical work when the text was indeed intended to deliver her reflective ideas. ${ }^{26}$ At this point, with the previous and current methodological considerations, some

the term 'hermeneutic' to express what is meant by 'interpretation'. Here I do not claim to give a complete account of the issue of philosophical interpretation, which deserves much more in-depth examination than what is given here, but only address some relevant aspects of the issue to my current discussion in this article.

${ }^{25}$ It is another matter when a thinker intentionally uses some seemingly paradoxical remarks to make some points. However, such occasions imply neither that the ideas delivered by these remarks per se are actually incoherent nor that the points in question could not be delivered effectively in clearer terms without paradoxical appearance.

${ }^{26}$ Fung Yu-lan made this point in his widely-used textbook on the history of Chinese philosophy (Fung 1948, 11). Various scholars have then also pointed out the point. For example, Kwong-loi Shun clearly explains this point and well illustrates it with his outstanding case study of Confucian-Mencian ethical thought in Shun 1997. 
further elaborations of the thinker's line of thought and her surrounding reflective ideas via adequate conceptual and explanatory resources available to us (though not available to the thinker and thus "external" to her) are genuinely needed, instead of being a mere issue of preference, for the sake of enhancing our understanding of the thinker's ideas including their due implications. It is noted that "blurring" assimilation might result from "over"-use of external resources when interpreting one or both parties under comparative examination, especially when the external resources used to characterize one party come from the other party; however, for the purpose of philosophical interpretation, the resulting assimilation is not necessarily inappropriate but might illuminate the essential connection and common points (such as a jointly-designated object of study, which constitutes the same referential meaning) between the assimilated ideas at the fundamental level so as to enhance our understanding of those ideas; failing to realize or denying such an essential connection and common points (if any) while realizing and recognizing various differences only would result in "exaggerated distinction," which can be justifiably criticized in this case.

It is also important to note that an interpreter in a project in studies of Chinese philosophy with the philosophical-interpretation-concerned orientation, instead of a mere historicaldescription orientation can, or rather tends to, focus on a certain aspect, layer or dimension of a thinker's ideas based on the purpose of the project, the reflective interest of the interpreter, etc. Indeed, instead of a comprehensive coverage of all aspects or dimensions of the object of study, focusing on one aspect or dimension is a kind of simplification. Now the question is this: Is any simplification per se doomed to be indiscriminately a "sin" of oversimplification? Surely, when a project aims at accurately describing relevant historical matters of facts and pursue what the thinker under description actually thought, and what resources were actually used (by her), simplification in this connection is always oversimplification; any simplification is guilty of being negatively excessive and thus identical with falsification. Nevertheless, it should be clear that, if the purpose of a project is to focus on interpreting or elaborating one aspect or dimension instead of pretending to give a historical and sociological description, charging the practitioner of this project with oversimplification or doing something excessive in simplifying its working coverage into one aspect or dimension would be unfair and miss the point.

Indeed, a project on one object of study in cross-tradition philosophical engagement should be guided by a holistic understanding with a higher vantage point; that is why it is important to maintain an adequate methodological guiding principle which is to constitute one crucial part of such a holistic understanding at least in one's background thinking on the object of study. Clearly, neither such a "holistic" understanding as the guiding-principle dimension of a "complete" understanding of the object of study nor such a "complete" understanding as a whole lies merely in a historical and sociological description (even if a "comprehensive" one), whose employed perspective can be one of multiple (eligible) perspectives, instead of the exclusive one; these multiple eligible methodological perspectives are complementary and can make joint contribution to a complete understanding of the object of study. In this way, a reflective project in philosophy that takes a certain methodological perspective through focusing on one aspect of an object of study and a historical and sociological description of the object are not merely compatible but complementary to each other; both are indispensable for a complete understanding of the object. At this point, what needs to be recognized is an important distinction between a methodological perspective as a current working perspective and a methodological guiding principle that an agent presupposes when taking the methodological perspective and that would be used by the agent to guide or regulate how the current perspective would be applied and evaluated in view of 
some other eligible perspectives. As already emphasized before, one's reflective practice per se of taking a certain methodological perspective amounts to neither reflectively rejecting some other eligible methodological perspectives nor presupposing an inadequate methodological guiding principle which would render ineligible other eligible methodological perspectives (if any). What is at issue is whether the interpreter has assumed an adequate methodological guiding principle to guide and regulate how to look at the relation between the current methodological perspective used as a working perspective and other eligible methodological perspectives that would point to other aspects of the object of study. Consequently, when one evaluates a project in comparative philosophy, what really matters is for one to look at and understand what kind of methodological guiding principle is explicitly assumed or implicitly presupposed while taking the current working perspective.

Another methodological emphasis of the constructive-engagement strategy is on the relevance and significance of the thinkers' ideas and their related movements of thought to the common philosophical enterprise and contemporary development of philosophy. This emphasis is intrinsically related to one significant methodological orientation in studies of Chinese philosophy, i.e., the philosophical-issue-engagement orientation aiming at contribution to jointly-concerned philosophical issues as jointly-concerned object of study in comparative philosophy. The primary purpose of this orientation in studies of ancient thinkers is to see how, through reflective criticism and self-criticism, ancient thinkers under examination could constructively contribute to the common philosophical enterprise and/or a range of jointly-concerned issues of philosophical significance (such as the issue of truth examined here) ${ }^{27}$ rather than to focus on providing a merely historical or descriptive account or on interpreting some ideas historically developed in a certain tradition or account. Typically, with a certain jointly-concerned philosophical issue being addressed, some substantial ideas historically developed in distinct philosophical traditions or accounts are explicitly examined for the sake of figuring out how they could jointly and complementarily contribute to the jointly concerned issue in philosophically interesting ways. Insofar as crosstradition engagement in dealing with various common concerns and issues of philosophical significance is most philosophically interesting, this philosophical-issue-engagement orientation and its methodological strategy explicitly and constructively conducts philosophical engagement and is thus considered most philosophically interesting.

It should be noted that, if a project of study in Chinese philosophy explicitly with a single orientation (the interpretation-concerned orientation, the philosophical-issue-engagement orientation, or the historical-description-concerned orientation) is considered as a projectsimplex in studies of Chinese philosophy, a project in reflective practice concerning Chinese philosophy might be a complex that goes with a combination of two or more orientations. A comprehensive project concerned with a historical figure often consists of such a combination. Recognition of the characteristic features of the aforementioned distinct orientations/purposes and their respective methodological approaches would help us discriminatively treat, and evaluate, different stages or parts of a project-complex in studies of Chinese philosophy. It is important to note that the emphasis on the philosophical-issueengagement orientation and the interpretation-concerned orientation in studies of Chinese

\footnotetext{
${ }^{27}$ It is arguably right that many issues that were traditionally identified as some "unique" issues in different traditions have turned to be concerned primarily with different aspects, layers or dimensions of some jointly concerned, more general issues of philosophy, especially from a more broadly philosophical vantage point and through due philosophical interpretation. This is one point that I have endeavored to make and illustrate in my several writings mentioned above.
} 
philosophy certainly would not deny the legitimacy and due value of the historicaldescription-concerned orientation as one effective approach; what is stressed here is the conceptual compatibility, constructive complementarity, and mutual enhancement of these distinct methodological orientations as complementary methodological perspectives when they are taken under the guidance of adequate methodological guiding principles.

It is also important to note that the identities of jointly-concerned issues of philosophy is not the same as the identity of the existing issue domain of inquiry: for their identities, the constructive engagement strategy resorts to neither the current agents' subjective preferences nor the identity of the existing domain of inquiry; rather, through some resources on adequacy conditions for methodological guiding principles to be introduced in Appendix 3, it has positively suggested a kind of "objective" criterion for the identities of such issues that can be jointly-concerned through philosophical interpretation.

\section{APPENDIX 3: \\ ADEQUACY CONDITIONS FOR LOOKING AT THE RELATION OF DISTINCT APPROACHES: FROM CONSTRUCTIVE-ENGAGEMENT VANTAGE POINT ${ }^{28}$}

In the following, I present a set of adequacy conditions for how to look at the relationship of distinct approaches to jointly-concerned issues with adequate methodological guiding principles, i.e., the (meta) methodological emphasis (5) of the constructive-engagement strategy as highlighted at the outset of this section.

As indicated before, for the constructive-engagement purpose, it is especially philosophically interesting, relevant, or even crucial to maintain an adequate methodological guiding principle, which the agent is expected to hold in identifying the purpose and focus of a specific project, evaluating the status and nature of distinct eligible methodological perspectives, applying her own working methodological perspective regarding the specific project, and looking at the relationship between her current working perspective and other methodological perspectives. In the following, I give a brief presentation of a set of ten conditions for adequate methodological guiding principles ("adequacy conditions" for short), which are not considered exhaustive, exclusive, or dogmatic; they are open to criticism for their validity and explanatory force. ${ }^{29}$

$<1>$ The same-object-recognizing condition (against the "anything-goes" orientation or radical relativism). A methodological guiding principle is considered adequate (in this connection) if, given an object of study, it enables the agent to recognize that there is a way that the object objectively is such that it is not the case that "anything goes," and we can all talk about that same object even though we may say different things (concerning distinct

\footnotetext{
${ }^{28}$ The content of Appendix 3 is a modified version of an excerpt from Mou 2016 in which the addressed account of the ten adequacy conditions is a substantial expansion and re-organization of the relevant content of Section 2. of Mou 2010 (where the first adequacy condition (i.e., the same-objectrecognizing condition) is treated as one basic, minimal metaphysical assumption as given in Section 2.1 , together with six adequacy conditions as given in Section 2.4).

${ }^{29}$ Earlier versions of the adequacy conditions are presented with elaboration and illustrations in Mou 2010 and Mou 2016. To save space, I present the set of adequate conditions without using sample perspectives for illustration [except for Condition (9) which needs illustration for clarification and better understanding, given in its note]. For more explanation of them with illustration, the interested reader can see the aforementioned writings.
} 
aspects of the object) about it. ${ }^{30}$ In contrast, it is considered inadequate (in this connection) if otherwise. This adequacy condition may be called a basic "way-things-are-capturing" condition in the sense that it is presupposed by the remaining types of adequacy conditions for the sake of capturing the way the object is (or is to be), given that the truth pursuit (i.e., the "way-things-are-capturing" pursuit) is one strategic goal for any reflective pursuits of "how things are" (instead of "anything goes" or "mere intellectual game playing").

$<2>$ The perspective-eligibility-recognizing condition. A methodological guiding principle that is held or presupposed by the agent who uses some eligible methodological perspective concerning an object of study as her current working perspective is considered adequate (in this connection) when this guiding principle renders other eligible methodological perspectives (if any) also eligible and somehow compatible with the application of the current working perspective. In contrast, it is considered inadequate (in this connection) if otherwise. This adequacy condition may be called a "minimal" multipleperspectives-treating condition in the sense that it is presupposed by the remaining kinds of adequacy conditions concerning how to look at the relationship between distinct perspectives.

$<3>$ The agent-purpose-sensitivity condition. A methodological guiding principle is considered adequate (in this connection) if it enables the agent to have her choice of a certain working perspective, among eligible methodological perspectives concerning an object of study, sensitive to the agent's purpose and thus renders the most applicable or the most appropriate (the best relative to that purpose) the perspective that (best) serves that purpose. In contrast, it is considered inadequate (in this connection) if otherwise.

$<4>$ The equality-status-granting condition. A methodological guiding principle is considered adequate (in this connection) if it renders all the eligible methodological perspectives (perspective simplexes) concerning an object of study equal in the following sense: being equally in need for the sake of a complete account of the object, although one eligible perspective can be rendered more in need or in focus than others only relative to its associated purpose when it is taken in a specific project; thus none of them is absolutely superior (or inferior) to the others in the above sense. In contrast, it is considered inadequate (in this connection) if otherwise. It is noted that the equality-status-granting condition in the foregoing sense does not necessarily render all eligible perspectives equally local: if the addressed eligible perspective does point to and capture a certain "universal" or "essential" base layer (if any) of the object that gives one defining identity of the object (in view of the other objects of the same "universally-identified" kind and of its "unifying" role), an adequate methodological guiding principle would render it basic instead of merely local,

\footnotetext{
${ }^{30}$ As indicated in my previous writings (say, Mou 2010 and 2016) on this, the identity of a (genuine) object of study in philosophy is understood broadly: whether it is a naturally produced object in physical reality, a socially constructed object in social reality, an abstract object out of theoretic construction, or an 'linguistic' object which are introduced linguistically, or an issue or topic in philosophical inquiries (such as the issue of (filial piety) as a jointly-concerned object of study in Socrates' and Confucius' teachings, which is used in my 2010 paper for illustration). Also note that, if an object of study, whether it is an object in a straightforward sense (like a house, a human being, etc.) or an object of philosophical inquiries as an issue or topic (like the issue of truth under examination here) is a genuine object of study in philosophy, it should be referentially accessible and communicable and open to reflective criticism; in contrast, a pseudo object of study in philosophy does not really possess genuine aspects that are referentially accessible and critically communicable among participants in philosophical dialogue; in this sense, a pseudo issue in philosophy cannot be really "given" as an object of study or justifiably assumed in philosophical inquiry, whether or not it can be assumed as a legitimate object of study in some other kinds of inquiry (say, in social psychology).
} 
although one basic eligible methodological perspective is not necessarily or always in current focus (as one current working perspective) in specific projects with their distinct purposes.

$<5>$ The new-eligible-perspective-possibility-recognizing condition. A methodological guiding principle is considered adequate (in this connection) if it enables the agent to have an open-minded attitude toward the possibility of a new eligible perspective concerning an object of study that is to point to some genuine aspect of the object but has yet to be realized by the agent because of the "unknown-identity" status of that aspect. A methodological guiding principle is considered inadequate (in this connection) if otherwise.

$<6>$ The dynamic-development-sensitivity condition. A methodological guiding principle is considered adequate (in this connection) if it guides the agent to be sensitive to the dynamic development (if any) of an object of study for the sake of realizing and understanding which aspects are (still or currently) genuinely possessed by the object (thus which methodological perspectives are still eligible) and which ones are not (thus which perspectives not currently eligible anymore). In contrast, it is considered inadequate (in this connection) if otherwise. This adequacy condition calls the agent's attention and sensitivity to this: during the process of the dynamic development (if any) of an object of study, the object might develop some new aspect(s) while losing some of its previous aspects; consequently, the methodological perspective with regard to the previous aspect of the object might not be absolutely or permanently eligible, and a previously ineligible perspective might become eligible because of its pointing to the new aspect. This adequacy condition highlights the need for the agent's sensitivity to the dynamic development (if any) of the object of study, one important front which can be easily ignored by an agent who is guided by an inadequate methodological guiding principle in this connection.

$<7>$ The direct-complementarity-seeking condition. Given that multiple, seemingly competing eligible methodological perspectives concerning an object of study, whose identity can result from dynamic development if any, turn out to be directly complementary (in the sense that they point to and capture distinct and complementary aspects or layers of the object, which jointly contribute to the identity of the object in a mutually-supportive and supplementary way, and thus are indispensable for a complete understanding of the object), a methodological guiding principle is considered adequate (in this connection) if it captures the complementary character of the involved aspects of the object and thus seeks the complementary connection and harmonious balance between those perspectives for the sake of capturing the way the object is in this connection. In contrast, it is considered inadequate (in this connection) if otherwise.

$<8>$ The sublation-seeking condition concerning guiding-principle-associated perspective complexes with complementary perspective simplexes. Given that there are two seemingly competing guiding-principle-associated perspective complexes concerning an object of study whose perspective parts are eligible (i.e., capturing distinct aspects of the object) but whose respectively associated methodological guiding principles are genuinely competing or incompatible (either because one of them is inadequate or because both are inadequate in other connections addressed above), such a methodological guiding principle would be considered adequate (in this connection) if it seeks a due solution through a Hegelian synthetic balance via sublation that keeps what are reasonable or appropriate from both guiding-principle-associated perspective complexes (i.e., their eligible perspectives, maybe plus some adequate guiding principle from one perspective complex if any) while disregarding what are not, i.e., the inadequate guiding principle (or principles) in one (or both) of the perspective complexes. In contrast, it is considered inadequate (in this connection) if otherwise. 
$<9>$ The contradiction (if any)-recognizing-while-indirect-complementarity-seeking condition (concerning genuinely competing perspectives). Given that two different seemingly competing but eligible methodological perspectives concerning an object of study, whose identity can result from dynamic development if any, turn out to be genuinely "contradictory" (in the sense that they point to and capture distinct aspects or layers of the object, which jointly contribute to the identity of the object but also jointly capture some internal contradiction really possessed by the object, and thus are indispensable for a complete understanding of the object), a methodological guiding principle is considered adequate (in this connection) if it $<\mathrm{i}>$ captures the genuine-contradiction state of the involved aspects of the object, $<\mathrm{ii}>$ recognizes the eligibility of these thus "contradictory" perspectives, and $<$ iii $>$ seeks a certain "constructive equilibrium" between those perspectives in a way sensitive to specific situation and with a due understanding of the status of the addressed internal "contradiction." In contrast, it is considered inadequate (in this connection) if otherwise. ${ }^{31}$

$<10>$ The open-mind-oriented self-criticism condition. This condition is listed last but not least; though the foregoing conditions, especially $<5>$ and $<9>$ implicitly point to this condition, it is reflectively worth specifying and highlighting separately, as this condition would fundamentally distinguish a genuinely philosophical attitude towards distinct critical views from an absolutely faith-oriented attitude that takes its foundation thing for granted and would not allow any criticism and challenges to it. The point of this condition is not that one cannot firmly maintain one's foundation thing or some axiom-like basic principle - it is clear that one has to stop somewhere in one's account or theoretic system; rather, the point of this condition is this: one needs to always maintain an open-minded reflective attitude towards all critical challenges to the basic principle on which one's account or theoretic system is based

\footnotetext{
${ }^{31}$ In other words, given that some internal contradiction really exists in the object and substantially contributes to the identity of the object, this adequacy condition consists of three layers: (i) recognizing that some genuine contradiction is possessed by the object and brings about a certain internal tension of the object (it is noted that this does not go against but actually maintains the truth-pursuit norm. Truth-pursuit is to reflectively pursue capturing the way things are (are to be). [If there is a genuine contradiction, then recognizing this genuine contradiction (or the "contradictory" dimension of an object) is actually implementing the norm, rather than violating it. The truth-pursuit norm does not automatically or necessarily mean that there is one single static entity waiting there for one's discovery. Indeed, the truth-pursuit norm includes reflective pursuit of capturing the way things are to be, especially for some social issues as objects of study. I do not examine this connection of the philosophical issue of truth in the current writing, with consideration of the purpose here, but explore it in another article.] (ii) thus recognizing that each of the involved perspectives that does point to and capture one of the "contradiction" aspects of the object is eligible and contributes to our understanding and treatment of the "contradictory" dimension of the object; (iii) point or through changing the original "contradictory" aspects to complementary aspects of the newly-developed identity of the object (thus "directly"), we can constructively render the originally "contradictory" perspectives "complementary" (mutually supportive and supplementary in some connection and to some extent), rather than just negatively dismissing (the potentiality of) such "indirect complementarity." The above layer (iii) is to be implemented in distinct ways, being sensitive to the nature of different types of objects of study. It is also noted that such an "indirect complementarity" can be minimally and jointly sought and reached, in an indirect way (in the aforementioned connections) by the agents who might disagree to how to "resolve" the "contradiction" and/or how to treat some other relevant issues (i.e., independently of how the agents intend to "resolve" the "contradiction" and treat some other relevant issues). For some sample cases (respectively regarding social reality and physical natural world) for illustration, see Mou 2018b, 22.
} 
and is ready to modify, revise, or even give up the basic principle if it turns out to be wrong or mistaken through critical examination and reasonable justification. In this way, any methodological guiding principle that has such an open-minded self-critical character and thus meets this condition would be adequate in this connection. If otherwise, a methodological guiding principle would be inadequate in this connection.

Several notes are due here. First, condition $<1>$, given an object of study, is presupposed by the remaining types of adequacy conditions as the truth pursuit (capturing the way the object is) is taken as one strategic goal for any reflective pursuit of "how things are" against the radical "anything goes" relativism. Second, condition $<2>$ is presupposed by the subsequent types of conditions $<3>$ through $<9>$. Third, if the relation between eligible methodological perspectives under consideration is really complementary, then one needs to resort to condition $\langle 7>$; if they appear to be not complementary, then we really need to have further examination of whether any of these perspectives is a perspective simplex or a "guiding-principle-associated" perspective complex (i.e., a combination of one perspective simplex plus a methodological guiding principle, as specified in Section 1.5.1); if it is the latter, one needs to resort to condition $<8>$; if it is the former, one needs to resort to condition $<9>$. Fourth, however, to thoroughly fulfill conditions $<1>$ and $<2>$, condition $<6>$ needs to be met if the object has its dynamic-development dimension. Fifth, last but not least, in the same philosophical spirit as what is indicated in the foregoing adequacy condition $\langle 10>$, any on this "adequacy-condition" list per se is open to criticism, instead of being dogmatically imposed. Indeed, this set of adequacy conditions is suggested here to serve two purposes: for one thing, it is to explain how it is possible to have adequate methodological guiding principles in cross-tradition philosophical inquiries; for another thing, it is to provide readers with an engaging starting point or an effective stepping stone, which per se is not intended to be dogmatically imposed on readers but expected to be a target of critical examination in their own engaging explorations of the issue.

The forgoing adequacy conditions can also contribute to suggesting an "objective" criterion for the identities of those issues that can (and should) be jointly-concerned (through appropriate philosophical interpretation). As indicated before, the identities of the jointlyconcerned issues of philosophy are not the same as, and cannot be exhausted by, the identities of those issues in the existing domain of inquiries: for their identities, the constructive engagement strategy presupposes neither the current agents' subjective preferences nor the identities of the issues in the existing domain of inquiries; rather, as highlighted in the preceding adequacy conditions $<5>$ and $<6>$, i.e., the "new-eligible-perspective-possibilityrecognizing" condition and the "dynamic-development-sensitivity" condition, the constructive-engagement strategy is explicitly inclusive to cover both newly-identified aspects of an object of study during the process of our further exploration of the object and newly-developed aspects of an object of study during the process of its dynamic development, both of which are open to newly-developed eligible perspectives; in this sense and to this extent, through the suggested set of adequacy conditions, the constructiveengagement strategy can positively contribute to characterizing some "objective" criterion for the identities of those issues that can be jointly-concerned (through due philosophical interpretation). It is also noted that some problems or issues that were previously identified as different or separate problems or issues, which were (in some cases) further taken to belong to different traditions, turn out to be distinct aspects or layers of a larger or underlying issue as a whole. 


\section{APPENDIX 4: \\ A CASE ANALYSIS OF HALL-AMES PRAGMATIST APPROACH: FROM THE CONSTRUCTIVE-ENGAGEMENT VANTAGE POINT ${ }^{32}$}

1.

As far as the contemporary scholarship on Confucius' thought on tian (天), tian-ming (天命) and zhi-tian-ming (知天命) is concerned, in the following, I give an engaging examination of one influential but controversial interpretation, i.e., David L. Hall's and Roger T. Ames' interpretative approach ("the Hall-Ames approach" for short below), ${ }^{33}$ in the contemporary scholarship on Confucianism for three considerations. First, as far as the engaging discussion on the topic is concerned, although the Hall-Ames approach is remarkably controversial, I render it reflectively interesting and engaging; an evaluative analysis of it can enhance our understanding of the value and significance of Confucius' account of tian, tian-ming and zhitian-ming. Second, an engaging discussion of it from the "constructive-engagement" vantage point can effectively show how the constructive-engagement strategy as one general methodological strategy in cross-tradition engagement can identify and distinguish the reasonable part of one approach from its controversial part in a reasonable while engaging way. Third, the Hall-Ames approach treats truth (if any) as a pragmatic notion that plays its role ${ }^{34}$ in this engaging discussion, through explaining how the two basic norms play its indispensable foundational role in philosophical and other intellectual pursuits of "how things are," I will explain in which way and to what extent the Hall-Ames approach together with its conception of "pragmatic truth" actually presupposes, or is based on, the "way-things-arecapturing" understanding of truth (or "semantic truth"), whether or not Hall and Ames would realize and recognize it. Fourth, the Hall-Ames approach is also influential and representative as some take variant versions of essentially the same Hall-Ames approach; to this extent, the methodological point of my evaluative discussion of it can be more or less applied to these variant views. My strategy is this: first, I give an examination of some key points of the HallAmes approach that well present its "perspective" dimension and its "guiding-principle" dimension; second, I give an evaluative analysis of the status and nature of the two dimensions of the Hall-Ames approach; third, I address the issue of how the Hall-Ames approach is (descriptively) and needs to be (prescriptively) regulated and guided by the two fundamentally shared basic norms on which the debating parties need to observe for the sake of their approaches being philosophically interesting, engaging and relevant.

In its interpretation of Confucius' conception of tian, tian-ming and zhi-tian-ming, the Hall-Ames approach starts with criticizing Mou Zongsan's Kantian-style characterization of the "transcendental" character of tian. The Hall-Ames approach then resorts to what is viewed as the textual evidence in the Analects that shows the "anthropomorphic" character of Confucius notion of tian and tian-ming:

In the Analects, tian is unquestionably anthropomorphic.... [Confucius'] conceptions of tian retains a residue of anthropomorphism evident in tian's capacity for conscious intervention in human affairs... The portrait of tian that emerges from an analysis of relevant passages in the Analects is one that clearly has some anthropomorphic characteristics...tian [is thus] unqualifiedly immanent...tian is not a preexisting creative principle which gives birth to and

\footnotetext{
${ }^{32}$ The contents of Appendix 4 are excerpts (with modifications) from Chapter 5 of Mou 2019.

${ }^{33}$ Primarily in Hall and Ames 1987.

${ }^{34}$ Also see Hall 1997 and 2001.
} 
nurtures a world independent of itself. Tian is rather a general designation for the phenomenal world as it emerges of its own accord. Tian is wholly immanent, having no existence independent of the calculus of phenomena that constitute it. There is as much validity in asserting that phenomena "create" tian as in saying that tian creates phenomena; the relationship between tian and phenomena, therefore, is one of interdependence. The meaning and value of tian is a function of the meaning and value of its many phenomena, and the order of tian is expressed in the harmony that obtains among the correlative parts. ${ }^{35}$

The Hall-Ames argumentation line here seems unclear or unconvincing in several connections. First, the fact per se of using personification terms to non-human things is not strong textual evidence for the "anthropomorphic" interpretation of Confucius' conception of tian, as making metaphoric statement by using personification terms to non-human things is quite normal (or even more or less popular) way in any natural languages, in both ancient and modern times, in Chinese and other natural languages. ${ }^{36}$ That is, using such metaphoric expressions does not necessarily mean presupposing that such things have consciousness with intentions like human beings and does not necessarily point to an "anthropomorphic" language with the foregoing "cosmological" presupposition. What these phrases really mean need to also consult the contexts as a whole where they appear. It is arguably correct that these cited pieces of textual evidence are well open to a naturalistic interpretation. For example, let us look at the contexts of 17.19 of the Analects where a metaphoric use of "tian" appears ${ }^{37}$ : in 17.19: "What does tian ever say [an 'anthropomorphic' metaphoric use of tian]?"; immediately after this, it is a totally naturalist explanation: "four seasons turn and the myriad things are born and grow within it" (Hall's and Ames' own translation).

Second, on the other hand, there are also some prominent passages in the Analects that well show a non-"anthropomorphic" naturalist outlook, even if some of them can be also given an "immanent phenomena"-aspect-concerned interpretation to the extent to be explained below. Let me focus on one of such cases which Hall and Ames cite and give their own favored interpretation, as their interpretation of this case well shows how the Hall-Ames approach works when critically engaging with some other interpretative approach. There is the following passage (〈顏淵〉12.5) in the Analects, as noted by Hall and Ames ${ }^{38}$ :

\footnotetext{
${ }^{35}$ Hall and Ames 1987, 205-6. [With minor pinyin Latinization replacement.]

${ }^{36}$ For example, the native Chinese speakers often refer to the natural force in the natural world or fate beyond human control in metaphoric terms such as "liao-tian-ye"'(老天爺', which can be literally translated into "the Heaven Father"), even if the language users intend to fight against the fate. It is noted that those who fight against "the fate" do not necessarily mean that they deny the existence of the due way of reality and thus the need to capturing it; it might be the case that what they fight against, in their eyes, is un-due part of the world, although it is another issue whether one can really capture the due way of reality. The point here is that the metaphoric use of language expressions, as one widelyemployed linguistic means (in both ancient and modern times, in phonetic languages like English and ideographic languages like Chinese) is not necessarily associated with some substantial anthropomorphic commitment.

${ }^{37}$ Its Chinese original of the passage $<$ 陽貨 $>17.19$ in the Analects is this: 子曰：“予欲无言。”子贡曰：“子如不言，则小子何述焉？”子曰：“天何言哉？四时行焉，百物生焉， 天何言哉?”

${ }^{38}$ In their interpretative favor, their own translation with the minor pinyin Latinzation modification, together with the Chinese original, is used here).
} 
司馬牛憂曰：“人皆有兄弟, 我獨亡。”子夏曰：“商聞之矣 : 死生有命, 富貴在天。君子敬 而無失, 與人恭而有禮。四海之內, 皆兄弟也。君子何患乎無兄弟也?”

Sima Niu lamented, "Everyone has brothers except for me."

Zi Xia said to him: "I have heard the saying: Life and death are a matter of ming (命);

Wealth and honor lies with tian (天). The exemplary person (jun-zi) is deferential and faultless, respectful of others and refined, and everyone in the world is his brother. Why would the exemplary person worry about not having brother?"

Indeed, as realized by Hall and Ames, this passage is frequently cited in support of a naturalist interpretation of Confucius' account of tian and tian-ming as something beyond human control and independently of how humans wish (whether tian or tian-ming is interpreted as the way of this natural world or some destiny and fate); D. C. Lau takes the passage to be a best illustration of the point of Confucius' notion of tian or tian-ming. ${ }^{39}$ Hall and Ames comments on it this way:

First, we know that historically Sima Niu did in fact have a brother... Here Sima Niu disowns him and alters the apparently unalterable by refusing to interpret "brotherliness" in terms of "facticity". Zi Xia then does him one better by demonstrating that the reverse can be effected-a brotherless person can alter the conditions (that is, his ming 命) which cause him to be brotherless by redefining what it means to have brothers (that is, by changing its meaning and frame of reference, its "name," ming* 名). He asserts that the criterion of brotherhood can be moral (fraternal) rather than biological (born of the same womb). This passage, far from justifying fatalism, demonstrates the fluidity of ming and the inseparability of fact and value in the description of one's causal context, one's ming. ${ }^{40}$

Their foregoing comments well demonstrate not only the "perspective" dimension of the Hall-Ames approach but its "guiding-principle" dimension which guides them how to look at the relation between their working perspective and some other (naturalist) perspective. It is noted that, in the original text, $\mathrm{Zi} \mathrm{Xia}$ does not deny a naturalist account of tian and tian-ming although he also takes another perspective to look at the brotherhood; in this way, Zi Xia recognizes both perspectives here "eligible" and render "fact" (brotherhood in the biological sense) "separable" from value (brotherhood in the moral sense), rather than "inseparable". Now, when the Hall-Ames approach indiscriminately interprets Zi Xia as just claiming the "inseparability" of fact and value, this actually shows the "guiding-principle" dimension of the approach that treats its human-pragmatic "immanent-phenomena"-aspect-concerned perspective par-excellent or absolutely superior over the other "eligible" perspectives.

Third, the Hall-Ames approach emphasizes the "interdependence" between Confucius' tian and phenomena; this is an unconvincing point. It is not the case that everything in this natural world is within human control, unless Confucius is interpreted to be a Berkeley-like idealist thinker who would take the line to the effect that existence lies in being experienced. However, this would be a highly implausible interpretation of Confucius's position in this connection. Out of the principle of charity, it can be reasonably assumed that Confucius recognizes that the surrounding natural world exists independently of humans' mind (or, their heart-and-mind), that this natural world as a whole is beyond human control, and that humans can attuned themselves to it instead of manipulating it.

\footnotetext{
${ }^{39}$ Lau 1979, xxviii, where he states that it is "best illustrated by" the [12.5] context that "ming is used in the sense of Destiny and that Heaven is only a synonym for ming."

${ }^{40}$ Hall and Ames 1987, 214-5.
} 
Fourth, as already addressed in my comments in the foregoing second point, more generally speaking and methodologically speaking, one substantial difficulty with the HallAmes approach here is this: when arguing for its own perspective given that it is "eligible" in the sense that it does point to and capture some aspect or layer of the object under examination, it dismisses and rejects some other perspectives, which are also "eligible" in the sense that they point to and capture some other aspects or layers of the object under examination. As indicated above, Lau views the 〈顏淵〉12.5 passage as a best illustration of a naturalist interpretation without explicitly excluding other "perspectives" (if also "eligible"). In contrast, Hall and Ames comment that "[t]this passage, far from justifying fatalism, demonstrates...the inseparability of fact and value in the description of one's causal context, one's ming"; ${ }^{41}$ in so saying, they simply dismiss the "fatalism"-style naturalist interpretation and other non-"immanent phenomena"-aspect-concerned naturalist interpretations. The question is this: would Hall and Ames really think that fact and value are just indiscriminately and absolutely "inseparable" with regard to any parts of this natural world? The factual aspect and the value aspect can be unified by the same natural world both through the same human society and through the same natural world of which humans are parts; that does not amount to saying that they are just the same or the "inseparable"; the relation between fact and value has its "inseparate" aspect and its "separate" aspect, instead of indiscriminate "inseparability".

Indeed, from the point of view of the Hall-Ames-style "immanent-phenomenon"-aspectconcerned perspective that is human-pragmatically-oriented ("the immanent-phenomenonconcerned perspective" for short), it can be stated that things within the "phenomenon" aspect or layer of the natural world are "interdependent"; this perspective does point to and capture the "phenomenon" aspect or layer of the natural world, of which humans are parts and thus of which the "horizontal" fusions or "interface" portions (as the constituents of the "phenomenon" layer of the natural world) between humans and humans-felt surrounding natural world are parts. To this extent, the addressed immanent-phenomenon-concerned perspective is one "eligible" perspective; in other words, a range of statements that take this perspective ("the immanent-phenomenon-perspective-taking statements" for short) can be true to the extent that they point to and capture various aspects or features of the "phenomenon" layer of the way of the natural world. However, on the other hand, what the immanent-phenomenon-concerned perspective (generally speaking) and the immanentphenomenon-perspective-taking statements (specifically speaking) give are only "partial" truths in this sense: the addressed immanent-phenomenon-concerned perspective is only a finite and local perspective, which itself is not a multiple-perspective-combined perspective complex, not to mention a complete account.

That is exactly where we need a "transcendental" vantage point from which we can see the boundary and limit of such an immanent-phenomenon-concerned perspective as one finite and local perspective and thus can have an adequate methodological guiding principle regarding the due relationship between the "phenomenon"-aspect-concerned perspective and other "eligible" finite and logical perspectives. Indeed, Confucius' text, even if not in an articulate way but implicitly, shows such a "transcendental" vantage point as well as the aforementioned multiple perspectives, instead of taking one single finite perspective only.

The Hall-Ames approach might respond this way: why don't we take their immanentphenomenon-concerned perspective to be exclusive so that a pragmatist "human-phenomenaoriented" guiding principle, rather than treating a naturalist "transcendental" interpretation, is treated as an adequate guiding principle? Here we need to look at which would provide a

${ }^{41}$ Hall and Ames 1987, 215 (my emphasis in italics). 
best-explanation vantage point. First, the pragmatist "human-phenomena-oriented" guiding principle cannot provide a reasonable explanation of the relevant fundamental things: among others, (1) this interpretation line cannot explain the origin of this world so as to capture Confucius' underlying insight in this connection; (2) without the "independent" foundation and its related criterion that are beyond human control, this interpretation line per se can hardly escape from its running into a kind of radical "anything does" relativism and thus fails to do justice to Confucius' account of tian, tian-ming and zhi-tian-ming. In these two connections, there is a need to further look at how the Hall-Ames approach is related to the two fundamental common norms that are arguably shared, and need to be observed as guiding norms, by the debating parties that intend to be mutually understandable, philosophically interesting, engaging and relevant; in view of the general methodological relevance of the discussion on this issue and its being especially relevant to the topic here, I carry out this examination in the next section.

With the foregoing engaging explanation, now let me positively present the basic point of Confucius' conception of zhi-tian-ming, which constitutes one significant part of the truthconcern resources in the Analect. Indeed, although Confucius' text is open to the aforementioned distinct interpretations, one thing is certain: while rendering them closely related, Confucius conflated tian-ming (as the way of Heaven or the fundamental principle of this natural world) neither with the human beings' naturally-endowed nature nor with the human-intrinsically-involved "phenomena" world, even if he himself did not explicitly say much about such a relationship. First, in the Analects text, Confucius separately talked about tian-ming (the way of Heaven) and xing (human nature), rather than conflating each other; although he did not often talk about the two, when he did, Confucius did not treat them as the same. Second, Confucius indicates that, only eventually at his fifty-years old, he became to understand and capture tian-ming as the way of Heaven; however, as for human beings' naturally-endowed traits ("good" or "bad"), even ordinary people (certainly including Confucius himself) can more or less directly feel or observe them; it is not accidental that, when debating over whether human beings' original moral nature is good or bad, both Mencius and Xun Zi at least partially resorted to ordinary people's pre-theoretic observation, or their own moral psychology, of what kinds of original (moral) traits human beings have. In this way, although without further elaboration, Confucius maintains several points: (1) tianming (天命 the way of Heaven) and xing (性 human nature) are distinct and cannot be conflated; (2) to really understand and capture tian-ming, one needs to go through reflection via long-term cultivation, instead of merely relying on direct introspection of human (original) nature (whatever it is), even if the latter is (or can be) the former's manifestation; (3) tianming as the way of Heaven is normative in the sense that it guides how the natural world, of which humans and the human society are parts, is to go and thus tian-ming is the due way things in the universe (the natural world as a whole) are to be; (4) human morality if any is to be fundamentally in accordance with tian-ming as the due way things are to be, and to this extent human morality is part of the due way things are to be.

It is noted that we can use the term 'transcendent' in a naturalist way (rather than in a Kantian way) to characterize the "transcendental" character of tian and tian-ming as conceived in Confucius' account: when the term 'Heaven' is used in comparison and contrast to humans, it does not designate something beyond and above humans; rather, it designates the natural world as a whole with its "transcendental" character in the foregoing sense through which the Heaven as the natural world (as a whole) and humans as parts of the heaven are unified: its fundamental principle is neither limited to human affairs and the human society only (to this extent, involving human affairs is not "necessary") nor 
manifested by all the ways of human affairs (to this extent, involving human affairs is not "sufficient"). People's fundamental moral claims can be evaluated in view of the long-terms well-being of human beings in this natural world which is in accordance with the fundamental principle of the natural world of which the human society is part, although its various local manifestations can be distinct in view of various contextual contributing elements.

Indeed, human morality as part of the due way things (tian-ming as the fundamental principle of Heaven) are (to be) is neither absolutely "fixed" nor just "over there", as the way things (in this natural world of which humans are parts) are (to be) is never absolutely "fixed" nor just "over there". It is not absolutely fixed both because, generally speaking, human morality as part of the due way things are is not something in the platonic heaven but exists in the human society (as part of the natural world) that dynamically develops and because, specifically speaking, human morality as the human virtue with its associated moral account is never absolutely fixed but manifested in distinct ways sensitive to various relevant situational elements. ${ }^{42}$ Related to the foregoing point, human morality is not just "over there" because, from Confucius' vantage point, human morality in this world as part of the natural world is not separate from the human society of this world and from each of us; ${ }^{43}$ it is neither accidental nor mere luck for Confucius to eventually achieve spontaneous virtue (following his heart's desire without overstepping the bounds of propriety) at his seventy-years old after he understood and captured tian-ming (Heaven's Mandate, which including the due way of the human society) at his fifty-years old ${ }^{44}$ : the bounds of Heaven's Mandate have become intrinsic part of his spontaneous morality, instead of something imposed from outside just "over there"; the latter is fundamentally in accordance with the former. For Confucius, because human morality is to be in accordance with the fundamental principle of the natural world and thus part of its due way, one's morality via moral cultivation has to be pursued for its own sake and for its intrinsic value, with complete indifference to one's secular success or failure and to one's rewards after death or in this life; in this sense, it is more important than one's biological life. ${ }^{45}$

Then, at this point, Confucius' truth concern as one most fundamental concern in his teachings is quite natural: it is to capture the due way things are (to be) concerning human morality; as a jun-zi in full sense is an exemplar in capturing this, for Confucius, it is one's mission and fundamental strategic goal to become a jun-zi (to capture the way a jun-zi is to be). Consequently, capturing the due way things (in the human society as part of the inclusive natural world) are to be becomes one fundamental normative standard by which to judge the truth of an evaluative statement (such as "One should become a jun-zi" and "Confucius has become a jun-zi at his seventy-years old"). In this way, Confucius' truth-concern approach in this connection consists of two parts. First, it lies in its jun-zi-becoming moral cultivation pursuit as Confucius' way to present the strategic normative goal of truth pursuit in the foregoing sense. Second, it lies in its "due-way-things-are-capturing-via-becoming-jun-zi" normative standard by which to evaluate whether a moral evaluative statement is true or false,

\footnotetext{
${ }^{42}$ For example, from Confucius' vantage point, for the fundamental virtue ren (the humanity), see the Analects, <顏淵 $>12.5,<$ 里仁 $>4.3,<$ 子路 $>13.19,<$ 顏淵 $>12.1,<$ 雍也 $>6.28$; for the virtue of xiao (the filial piety), see the Analects, <為政> 2.5, 2.6. 2.7. 2.8.

${ }^{43} \mathrm{Cf}$., the Analects, <雍也 $>6.17,<$ 陽貨 $>17.2$.

${ }^{44} \mathrm{Cf}$., the Analects, $<$ 為政 $>2.4$.

${ }^{45}$ Cf., the Analects, $<$ 里仁 $>4.8,<$ 憲問 $>14.38$, <微子>18.7.
} 
a point to be further explained below. In both connections, so to speak, Confucius's truthconcern approach is his perspective elaboration of people's pre-theoretic "way-things-arecapture" understanding of truth concerning human morality.

2.

As indicated in the previous section, there is the need to further look at how the Hall and Ames approach is related to the two fundamental common norms that are arguably shared, and need to be observed as guiding norms, by the debating parties that intend to be philosophically interesting, engaging and relevant. Indeed, through the engaging discussion of the Hall-Ames approach to Confucius' conception of tian, tian-ming and zhi-tian-ming in the previous section, we can further think of one significant and especially relevant issue to cross-tradition/across-approach engagement in philosophy: as shown in the previous critical examination of the Hall-Ames approach, there seem to be so different interpretative approaches to Confucius conception of tian, tian-ming and zhi-tian-ming and so different accounts of the world of which humans are parts; we naturally raise one question: are these different approaches really engaging with each other or just telling their own stories but passing by each other without genuine engagement? Are there any fundamentally shared common bases which serve as norms on which the debating parties (need to) observe or agree on and which can serve as one criterion (if not the exclusive criterion) by which to make due evaluative judgment in this connection? Indeed, if otherwise (one party or both parties), it can be hardly really engaging: the debating parties then might either talk about different objects (instead of talking about the same object differently) and thus essentially pass by each other or have no basis on which to understand and evaluate each other in some substantial connections. Through the specific engaging discussion of the Hall-Ames approach as well as based on a due conceptual analysis in general, I contend that some shared basic norms can be, or actually explicitly or implicitly are, subscribed or resorted to by the really engaging parties and need to be so; to this extend, my subsequent remarks on such basic norms are both descriptive and prescriptive in nature.

One basic norm might as well be called the "same-object-recognizing" norm ("the sameobject norm" for short): given an object of study, the norm requires and enables the agent to recognize that there is a way that the object objectively is such that it is not the case that "anything goes", and we can all talk about that same object even though we may say different things (concerning distinct aspects of the object) about it. It is important to note that the identity of a (genuine) object of study in philosophy is understood broadly: an object of study can be a naturally produced object in physical reality, an event-like thing, a socially constructed object in social reality, an abstract object out of theoretic construction, a "linguistic" object which is introduced linguistically, a "textual" object as a thinker's text, an object of philosophical inquiry as an issue or topic, or this natural world of which humans and their activities and products are parts. In this way, when we all talk about that same object, we can take distinct perspectives that point to and capture different aspects or layers of the object, or of the way the object is (is to be).

Among others, one prominent, significant and fundamental manifestation or variant of the same-object norm is the same-natural-world norm to the effect that we (debating parties) all talk about the same natural world while talking about it differently, through distinct perspectives that point to and focus on different aspects or layers of it, with the due understanding of the identity of this natural world as a whole: we as humans and the human society are parts of it, its existence and development as a whole is independent of how humans think of it and beyond the humans' control, and any appropriate "local" principles of 
its parts are fundamentally in accordance with (rather than violating) its unifying "global" fundamental principle. This basic same-natural-world norm manifests its power in two connections or through two ways. First, the same-natural-world norm plays its direct guiding role in regulating our reflection on this natural world: we can all talk about the same natural world even though we may say different things (concerning its distinct aspects or layers) about it. Second, because this natural world directly, indirectly or arguably constitutes the fundamental metaphysical basis for a range of the fundamental human concerns, especially a range of issues in various subjects in philosophy (such as human morality), the same-naturalworld norm plays its fundamental guiding role through providing a due base for understanding the metaphysical foundation, source or direction of the adequate ways of these fundamental human concerns; to this extent, our reflective explorations of these fundamental human concerns need to be eventually based on and resort to the same-natural-world norm.

Indeed, the same-natural-world norm is especially relevant to the metaphysically-related context of philosophical exploration and plays its fundamental explanatory role for crosstradition/cross-approach engagement in philosophy. That is the case in the current engaging discussion of the Hall-Ames approach. Descriptively, as shown in the foregoing examination of their approach, and from the point of view of the principle of charity in philosophical interpretation, they do set out to talk about this same surrounding natural world as the one about which their opponents set out to talk, though they talk about this same natural world differently; if we render them talking about some different world from this natural world on which we live together and of which humans are parts, that would be an insult to them, instead of a praise, in two connections: first, that would amount to saying that what they talk about is a radically different world that is irrelevant to what their debating partners are talking about; second, what they have said about this radically different world would be at most fictionally interesting while sounding clever and fancy. Prescriptively, for the sake of having their approach really philosophically engaging with their critics and relevant to examining this natural world of which their addressed "phenomenal" world is part, the Hall-Ames approach need or should set out to talk about the same natural world as that which their critics are talking about, whether or not (descriptively speaking) they intend to go that way. Nevertheless, at this point, I need to recognize that some expressions in the presentation of the Hall-Ames approach in (Hall and Ames 1987) do appear so tricky and unclear that they can easily have the reader think that they are talking about a different "phenomenal" world that floats over and separates from this natural world in some crucial connections. But, again, from the point of view of the principle of charity in philosophical interpretation, we might as well read them as rhetoric or metaphoric remarks deviating from the foregoing main track.

Another basic norm is distinct but closely related to the foregoing the same-natural-world norm, which might as well be called the "way-things-are-capturing" norm. This norm is fundamentally and intrinsically implied or presupposed in people's basic mental lives at two levels. First, at the "folk" or "base" level, it is fundamentally and intrinsically presupposed in people's understanding of what counts as the human agent's believing (as one rudimentary mental activity of human beings): believing what is said (primarily) means (or is) believing that what is said captures/connects to the way the addressed thing is; in other words, in normal cases of statements (except of the "pretension" case), one believes what one thinks or says of an object captures (a certain aspect of) the way (in one's focus) the object is, although it is another matter whether what one thinks or says of the object really captures (the aspect of it). Second, at the reflective level, in any reflective pursuits addressing "how things are" (including the due way things are and the way things are to be), the "way-things-arecapturing" norm constitutes one of the most basic conceptual foundation. Given people's pre- 
theoretic "way-things-are-capturing" understanding of truth, the foregoing "way-things-arecapturing" norm can also be labeled "truth-pursuit" norm.

Three notes are due here. First, as far as the relation of the roles played by the norm at the two levels is concerned, the role played by the norm at the "folk" or "base" level through its being intrinsically involved or presupposed in believing endures at the "reflective" level to the extent that believing as one rudimentary mental activity of human beings constitutes one "base" or "base" layer of further "reflecting" activity and thus the mental activity at the "reflective" level is based on that at the "folk" level rather than being separated from the latter; in this way, at the "reflective" level, the role played by the norm is dual. Second, the present tense 'are' of the English verb phrase 'be' here is understood in the broader grammatical sense of the phrase 'present tense': it is not used to merely locate a situation or event in present time but more inclusive to locate situations or events that occurred in the past, or occurs in present time or at present, or will (or is to) occur in future time; in this way, "capturing the way things are" includes, rather than excluding, capturing the way things are to be (indicating a certain "prescriptive" point suggested in the literal sense of the phrase "are to be") or capture the "due" way things will be in accordance with things" own fundamental way in their development (if any), instead of whatever will occur in future time. Third, in view of the foregoing two notes, even those who claim that the objects of their reflective studies per se do not involve "fact" [as the way things are (to be)] but "value" cannot really escape from the guiding regulation of the "way-things-are-capturing" norm in two connections: (1) in the "believing" connection at the "base" layer of the reflective pursuit, they believe that what they say of the addressed thing captures the way the addressed thing is; (2) in the connection of what is under reflective pursuit, they intend to capture the due way the objects of their reflective studies are to be (should prescriptively be).

As explained in another writing (Mou 2019, Section 1.3) where the engaging background about distinct approaches to the issue of truth in studies of Chinese philosophy is introduced, essentially taking a revisionist attitude towards the pre-theoretic "way-things-are-capturing" understanding of truth, the Hall-Ames approach treats truth (if any) as a pragmatic notion that plays the role; ${ }^{46}$ now, when the Hall-Ames pragmatist approach treats truth (if any) as a pragmatic notion that plays the role, would that mean that such a kind of "pragmatist" approach together with its "revisionist" claim of the pragmatist notion of truth can really avoid the regulation and guidance of the fundamental "way-things-are-capturing" norm? As explained above, the norm is fundamentally and intrinsically implied or presupposed in people's basic mental lives in two connections or at two levels. At the "folk" or "base" level, there is no exception in the case of the Hall-Ames approach that the norm is fundamentally and intrinsically presupposed in the agent's believing (as one rudimentary mental activity of human beings): in normal cases of statements (except of the "pretension" case), believing what is said (primarily) means (or is) believing that what is said captures/connects to the way (given that it is a kind of "pragmatic" way, to be further targeted below) the addressed thing is. Then what seems to be at issue is whether, at the reflective level, the "way-things-arecapturing" norm constitutes one basic conceptual foundation even for the Hall-Ames approach as it explicitly takes a "revisionist" attitude towards people's pre-theoretic "waythings-are-capturing" understanding of truth and subscribes to a "pragmatic" notion of truth. One thing is certain: the Hall-Ames approach is also seeking capturing the "pragmatic" way the things in what is called "phenomenal" world are within their "pragmatic" perspective

${ }^{46}$ Cf., Hall 1997 and 2001. 
scope; to this extent the Hall-Ames approach is already regulated and guided by the "waythings-are-capturing" norm; but the case is stronger: if my diagnosis of how the Hall-Ames approach is fundamentally regulated and guided by the "same-natural-world" norm is correct, the "pragmatic" way (if any) human things are is fundamentally part of the way things in the natural world are: it is not merely part of the way things in the natural world are; it is part of the way of the unifying natural world; the "pragmatic" way (if it is one "due" way) human things are is neither the "status-quo" way nor the "anything goes" way human things are but is fundamentally guided and regulated by the fundamental way the unifying natural world is to this extent: the former is fundamentally in accordance with the latter without violation and fundamentally "manifests" the latter through the former's various specific manifestations which are sensitive to diverse contexts and situations and which might be not derivable or reducible to each other but fundamentally jointly unified by the latter. In this way, capturing the way things in the natural world in a holistic way not only covers capturing the "pragmatic" way [if it is a "due" way (as part of the way this unifying nature world is) human things are] but guides it fundamentally in accordance with the fundamental principle of this unifying natural world.

\section{ACKNOWLEDGEMENTS}

Again, as conveyed at the outset of the main text, I am warmly grateful to Soraj Hongladaron and Wei Sun for their extraordinarily helpful discussions and for their valuable contributions to the accomplishment of this "Constructive-Engagement Dialogue" section in the current issue of Comparative Philosophy. 1 am grateful to Christopher Framarin for his helpful comments on an earlier version of this essay. Partial ideas of this paper were presented at the invited session on comparative philosophy at the $24^{\text {th }}$ World Congress of Philosophy ( $15^{\text {th }}$ August 2018, Beijing, China); my thanks go to all those discussion participants on my presentation for their helpful questions and comments.

\section{REFERENCES}

Ames, Roger T. (with David L. Hall) (1987), Thinking through Confucius (Albany: SUNY Press).

- (with David L. Hall) (1995), Anticipating China: Thinking Through the Narratives of Chinese and Western Culture (Albany: SUNY Press).

- (with David L. Hall) (1998), Thinking from the Han: Self, Truth, and Transcendence in Chinese and Western Culture (Albany: SUNY Press).

- (2002), "David L. Hall (1937-2001)", Philosophy East and West 52.3: 277-280.

Cappelen, Herman \& Dever, Josh (2018), Puzzles of Reference (Oxford: Oxford University Press).

Davidson, Donald (2001), "Foreword" [on cross-tradition engagement], in Bo Mou (ed.) 2001a, v-vi.

Fung, You-lan (1948), A Short History of Chinese Philosophy (edited by Derk Bodde) (The Macmillan Company).

Hall, David L. (with Roger T. Ames) (1987), Thinking through Confucius (Albany: SUNY Press). 
- (with Roger T. Ames) (1995), Anticipating China: Thinking Through the Narratives of Chinese and Western Culture (Albany: SUNY Press).

- (with Roger T. Ames) (1998), Thinking from the Han: Self, Truth, and Transcendence in Chinese and Western Culture (Albany: SUNY Press).

- (2001), "The Import of Analysis in Classical China-A Pragmatic Appraisal", in Bo Mou (ed.), Two Roads to Wisdom?-Chinese and Analytic Philosophical Traditions (Chicago, Ill.: Open Court), 153-168.

Hongladaron, Soraj (2019), "How to Understand the Identity of an Object of Study in Comparative Philosophy", Comparative Philosophy 10.1: 119-126.

Lau, D. C. (trans. \& intro.) (1979), Confucius: The Analects (Penguin Books).

Mou, Bo (1997), "A Pragmatic Insight Regarding Morality: From A Comparative Perspective," in Weingartner, P.; Schurz, G.; and Dorn, G. (eds): The Role of Pragmatics in Contemporary Philosophy (Kirchberg, Austria), 659-664.

- (ed.) (2001a), Two Roads to Wisdom? ---Chinese and Analytic Philosophical Traditions (Chicago, Ill.: Open Court).

- (2001b), "An Analysis of the Structure of Philosophical Methodology: In View of Comparative Philosophy," in Mou (ed.) 2001a, 337-364.

- (2002). "Moral Rules and Moral Experience: A Comparative Analysis of Dewey and Laozi on Morality," Asian Philosophy 11.3: 161-178.

- (ed.) (2006), Davidson's Philosophy and Chinese Philosophy: Constructive Engagement (Leiden: Brill).

- (2010), "On Constructive-Engagement Strategy of Comparative Philosophy," Comparative Philosophy 1.1: 1-32: <http://www.comparativephilosophy.org>.

- (2012), "Some Thoughts on Identity of Islamic Philosophy," Comparative Philosophy 3:2: 36-40: <http://www.comparativephilosophy.org>.

- (2015), "Quine's Naturalized Epistemology and Zhuangzi's Daoist Naturalism: How Their Constructive Engagement is Possible," in Brian Bruya (ed.), The Philosophical Challenge from China (MIT Press), 303-337.

- (2016), "How Constructive Engagement in Doing Philosophy Comparative is Possible", Synthesis Philosophica 62.2: 265-277.

- (2018a), "A Double-Reference Account of Names in Early China", in Bo Mou (ed.), Philosophy of Language, Chinese Language, Chinese Philosophy: Constructive Engagement (Leiden, Netherlands: Brill), 69-169.

- (2018b), "General Introduction: Constructive-Engagement Strategy to Explore Chinese Philosophy", in Bo Mou (ed.), Chinese Philosophy: Critical Concepts in Philosophy (London and New York: Routledge), 1-28.

- (2018c), "On Adequacy Conditions for How to Adequately Maintain Methodological Guiding Principles to Look at Distinct Approaches", presented at the invited session on comparative philosophy at the $24^{\text {th }}$ World Congress of Philosophy, $15^{\text {th }}$ August 2018, Beijing, China. [Note: for its partial contents under discussion in this "ConstructiveEngagement Dialogue" section, see relevant parts in Mou 2016.]

- (2019), Semantic-Truth Approaches in Chinese Philosophy: A Unifying Pluralist Account (Lexington Book).

Shun, Kwong-loi (1997), Mencius and Early Chinese Thought (Stanford: Stanford University Press).

Sun, Wei (2019), "Pragmatic Approach or Constructive-Engagement Strategy?-A Methodology in Comparing Chinese and Western Philosophy", Comparative Philosophy 10.1: $127-142$. 